\title{
Effect of $\mathrm{Mg}^{2} \mathrm{p}$ ions co-doping on luminescence and defects formation processes in $\mathrm{Gd} 3(\mathrm{Ga}, \mathrm{Al}) 5 \mathrm{O} 12: \mathrm{Ce}$ single crystals
}

\author{
V. Babin ${ }^{a}$, P. Bohacek ${ }^{\text {a }}$, L. Grigorjeva ${ }^{b}$, M. Kucera ${ }^{c}$, M. Nikl ${ }^{a}$, S. Zazubovich ${ }^{\text {d, }}{ }^{*}$, A. Zolotarjovs ${ }^{b}$
}

\begin{abstract}

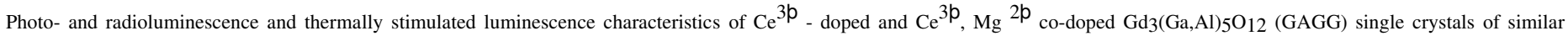

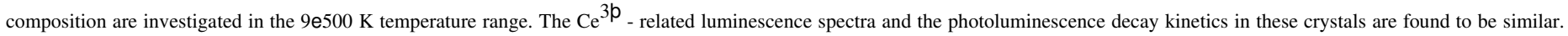

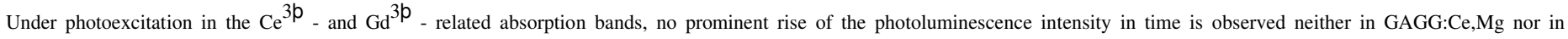

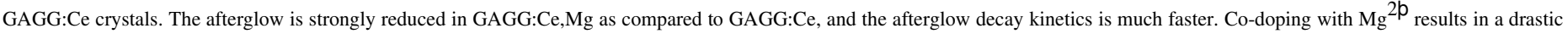

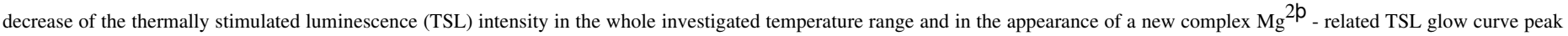

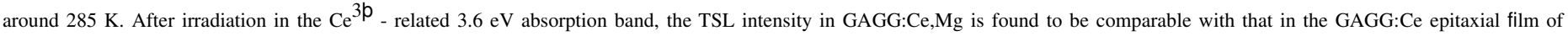

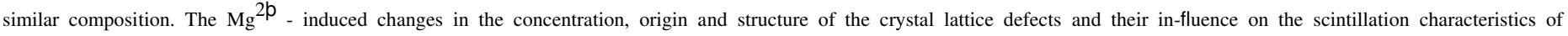
GAGG:Ce, Mg are discussed.
\end{abstract}

\section{Introduction}

In recent years, the $\mathrm{Ce}$ - doped $\mathrm{Gd}_{3} \mathrm{Ga}_{\mathrm{X}} \mathrm{Al}_{5} \mathrm{x}_{12}$ (GAGG:Ce) sin-gle crystals, ceramics and epitaxial films with different Ga contents were intensively studied as promising scintillator materials for their application in medical imaging because of their extremely high light yield, good energy resolution, relatively high density $\left(6.63 \mathrm{~g} / \mathrm{cm}^{3}\right)$, fast scintillation response, and high radiation stability and hardness [1e24]. Single crystals of $\mathrm{Gd}_{3} \mathrm{Ga}_{\mathrm{x}} \mathrm{Al}_{5} \mathrm{xO}_{12}: \mathrm{Ce}$ pre-pared by the micro-pulling down method were first reported in Ref. [1]. Their scintillation characteristics were found to be dependent on the Ga concentration. For the crystal with $\mathrm{x} 1 / 43$, the light yield of z42 000 photons/MeV, the dominating decay time of z53 ns, and the energy resolution of 8.3\%@662 keV were obtained. With the decreasing Ga content, the light yield and energy reso-lution were found to improve, but the decay time increases. The first $\mathrm{Gd}_{3} \mathrm{Ga}_{3} \mathrm{Al}_{2} \mathrm{O}_{12}$ : $\mathrm{Ce}_{\mathrm{single}}$ crystal grown by the Czochralski method with the light yield of 46000 photons/MeV and energy resolution of $4.9 \% @ 662 \mathrm{keV}$ was reported in Ref. [2]. Recently, an extremely high light yield of 58000 photon/ $\mathrm{MeV}$ and the best energy resolution of $4.2 \% @ 662 \mathrm{keV}$ were obtained for the single crystals of $\mathrm{Gd}_{3} \mathrm{Ga}_{\mathrm{x}} \mathrm{Al} 5 \mathrm{x} \mathrm{O} 12$ :Ce with $\mathrm{x} 1 / 42.7$ and $\mathrm{x} 1 / 42.4$, respec-tively, also grown by the Czochralski method [11]. Due to these characteristics, GAGG:Ce was considered as a promising scintillator for the PET application [2].

However, single crystals of GAGG:Ce showed relatively intense afterglow and thermally stimulated luminescence (TSL) due to the presence of antisite- and vacancy-related defects which act as effective traps for electrons. The preparation of Ce - doped garnets at much lower temperatures by the liquid phase epitaxy (LPE) method allowed to noticeably decrease the concentration of these defects (see, e.g., [25e27]). Scintillation characteristics of the LPE films of GAGG:Ce prepared with the use of a $\mathrm{BaO}-\mathrm{B}_{2} \mathrm{O}_{3}-\mathrm{BaF}_{2}$ flux were studied in Ref. [18], and their photo- and thermally stimulated luminescence were recently reported in Refs. [23,24]. 
The studies of $\mathrm{Gd}_{3} \mathrm{Ga}_{\mathrm{x}} \mathrm{Al}_{5} \mathrm{xO}_{12}$ :Ce showed that the increasing $\mathrm{Ga}$ content results in the high-energy shift of the $\mathrm{Ce}^{3 p}$ - related $5 \mathrm{~d}_{1}$ e $4 \mathrm{f}$ emission band and the lowest-energy $4 \mathrm{f}$ e $5 \mathrm{~d}_{1}$ absorption (excitation) band as well as in the low-energy shift of the $4 \mathrm{f}$ e $5 \mathrm{~d}_{2}$ excitation band $[6,24]$. The Stokes shift slightly increases as well. The decrease of both the crystal field strength and the band gap of the host material was observed (see, e.g. [4,6], and references therein). According to [6], the activation energy of thermal quenching of the $5 d_{1}$ e $4 f$ emission determined from the temper-ature dependence of the luminescence decay time decreases from $\mathrm{E}_{\mathrm{q}} \mathrm{z} 0.6 \mathrm{eV}$ for $\mathrm{x} 1 / 40$, to $\mathrm{E}_{\mathrm{q}} \mathrm{z} 0.5$ eV for $x 1 / 41$, to $E_{q} z 0.25$ eV for $x 1 / 43$ and to $E_{q} z 0.1 e V$ for $x 1 / 44$. In Ref. [23], the energy distance between the excited $5 \mathrm{~d}_{1}$ level of $\mathrm{Ce}^{3 \mathrm{p}}$ and the bottom of the con-duction band was directly determined by the TSL method and found to decrease with the increasing Ga content.

Recently it was found that a considerable improvement of scintillation characteristics can be also achieved by the co-doping of GAGG:Ce crystals with divalent alkali-earth ions, e.g., with $\mathrm{Mg}^{2} \mathrm{p}$ or $\mathrm{Ca}^{2} \mathrm{p}[5,14,15,19]$. Indeed, the studies $[5,14]$ showed that the $\mathrm{Ca}^{2 \mathrm{p}}$ co-doping of Czochralski grown GAGG:Ce results in a strong reduction of the afterglow and TSL at $\mathrm{T}<300$ $\mathrm{K}$. It also results in a noticeable improvement of timing characteristics of the material which is very important for PET applications. However the light yield of GAGG:Ce,Ca was found to be considerably lower as compared to GAGG:Ce. Besides, a new intense TSL peak at $390 \mathrm{~K}$ appears at the TSL glow curve of GAGG:Ce,Ca indicating the for-mation of deep electron traps. The $\mathrm{Mg}^{2} \mathrm{p}$ co-doping was found to have much better influence on the scintillation characteristics of GAGG:Ce as compared with the $\mathrm{Ca}^{2 \mathrm{p}}$ codoping [15,19]. Indeed, the GAGG:Ce,Mg crystals showed considerable improvement of the timing performance (much faster decay and rise times of the scintillation pulse with consequent improvement of the coinci-dence time resolution) and comparatively smaller light output decrease with the increasing $\mathrm{Mg}$ concentration.

It was also found that co-doping of various $\mathrm{Ce}$ - doped materials with divalent ions $\left(\mathrm{M}^{2 \mathrm{p}}\right)$ results in the change of cerium valence state from $\mathrm{Ce}^{3 \mathrm{p}}$ to $\mathrm{Ce}^{4 \mathrm{p}}$ (see, e.g. [28e30], and references therein). Both the $\mathrm{Ca}^{2 \mathrm{p}}$ and $\mathrm{Mg}^{2 \mathrm{p}}$ co-doping was found to stimulate the appearance of $\mathrm{Ce}^{4 \mathrm{p}}$ centers also in GAGG:Ce crystals $[5,14,15,19]$. The presence of $\mathrm{Ce}^{4 \mathrm{p}}$ is manifested by appearance of a broad ab-sorption band in the $4 \mathrm{e} 6 \mathrm{eV}$ energy range caused by an electon transfer from the valence band to the ground $4 \mathrm{f}$ state of the $\mathrm{Ce}^{4 \mathrm{p}}$ ion. In the crystal where the Ca content is two times larger as compared with the Ce content, the $\mathrm{Ce}^{4 \mathrm{p}}$ centers considerably outweigh the $\mathrm{Ce}^{3 \mathrm{p}}$ centers [14]. Only the presence of such excellent electron traps as the $\mathrm{Ce}^{4 \mathrm{p}}$ ions in the $\mathrm{M}^{2 \mathrm{p}}$ co-doped GAGG:Ce crystals can explain a strong suppression of slow components in the scintillation decay, since it prevents electron capture at various intrinsic defects and provides an alternative channel for fast radi-ative recombinations (for more details, see, e.g. [14,15,19], and references therein).

However, the mechanism of processes resulting in the light yield reduction in the co-doped crystals as well as the reasons of different influence of the $\mathrm{Ca}^{2} \mathrm{p}$ and $\mathrm{Mg}^{2} \mathrm{p}$ co-doping on the light yield reduction were not understood. The TSL characteristics as well as the origin and parameters of the traps in GAGG:Ce, Mg were not studied. Therefore, it was of great interest to understand the influence of $\mathrm{Mg}^{2 \mathrm{p}}$ ions on the defect structure, characteristics of the electrons and hole traps, energy levels of $\mathrm{Ce}^{3 p}$ and $\mathrm{Ce}^{4}$ $p$ ions, and recombination processes in GAGG:Ce. In the present work, the characteristics of the photo- and X-ray excited luminescence and thermally stimulated luminescence of GAGG:Ce and GAGG:Ce,Mg single crystals of approximately the same composition prepared by the Czochralski method are investigated in a wide temperature range $(9 \mathrm{e} 500 \mathrm{~K})$ and compared. The characteristics of the single crystals are compared with the corresponding characteristics of the GAGG:Ce epitaxial films studied in Refs. $[18,23,24]$. Absorption and radioluminescence spectra of the investigated single crystals, as well as their scintillation characteristics measured at room tem-perature have been reported in Ref. [19].

\section{Experimental procedure}

Single crystals of GAGG:Ce and GAGG:Ce, $\mathrm{Mg}$ were grown using the Czochralski technique (for more details, see Ref. [19]). The composition of the samples was analyzed using an electron probe microanalysis and was found to be $\mathrm{Gd} 3.027 \mathrm{Ga} 2.831 \mathrm{Al} 2.135 \mathrm{O} 12: \mathrm{Ce} 0.0071$ in GAGG:Ce and $\mathrm{Gd}_{3.046} \mathrm{Ga}{ }_{2.694} \mathrm{Al} \mathrm{O}_{2.253} \mathrm{O}_{12}: \mathrm{Ce}_{0.005} \mathrm{Mg}_{0.0022}$ in respect to $\mathrm{Gd}$, the Ce concentration was 0.237 at.\% in GAGG:Ce and 0.167 at.\% in GAGG:Ce,Mg. The Mg concentration in the GAGG:Ce,Mg crystal was 0.073 at.\%. The $\mathrm{Gd} 3.02 \mathrm{Ga} 2.7 \mathrm{Al} 2.26 \mathrm{O} 12$ :Ce 0.02 (5LGB5) epitaxial film was grown in Ref. [18] by isothermal dipping liquid phase epitaxy from $\mathrm{BaO}-\mathrm{B}_{2} \mathrm{O}_{3}-\mathrm{BaF}_{2}$ flux onto Czochralski grown $\mathrm{Gd} 3 \mathrm{Ga} 5 \mathrm{O} 12$ substrate. The concentration of $\mathrm{Ce}$ in the film was about 0.7 at. $\%$ and the film thickness, of $25.5 \mathrm{~mm}$. The above-mentioned samples were used for the photoluminescence, X-ray-excited luminescence and thermaly stimulated luminescence studies. For the investigations of the photoluminescence decay kinetics, the GAGG:Ce (Gd3.047Ce0.0041$\left.\mathrm{Ga}_{2.695} \mathrm{Al}_{2.254} \mathrm{O}_{12}\right)$ and GAGG:Ce, $\mathrm{Mg} \quad\left(\mathrm{Gd}_{3.011} \mathrm{Ce}_{0.0044} \mathrm{Mg}_{0.0021}\right.$ Ga2.644Al2.339O12) single crystals [19] and the GAGG:Ce epitaxial film $(\mathrm{Gd} 3.04 \mathrm{Ga} 2.98 \mathrm{Al} 1.96 \mathrm{O} 12: \mathrm{Ce} 0.02$ - 5LGB7) grown onto $\mathrm{Y} 3 \mathrm{Ga} 5 \mathrm{O} 12$ substrate [18] were used.

The steady-state emission and excitation spectra in the $90 \mathrm{e} 500 \mathrm{~K}$ temperature range were measured using a setup, con-sisting of the LOT ORIEL xenon lamp (150 W) and two mono-chromators (SF - 4 and SPM - 1). The luminescence was detected by a photomultiplier (FEU - 39 or FEU - 79) connected with an amplifier and recorder.

Luminescence decay curves $\mathrm{I}(\mathrm{t})$ were measured with a custom made 5000 M model of Horiba Jobin Yvon spectrofluorometer under excitation with a nanosecond coaxial hydrogen-filled flash-lamp (Eexc 1/4 $4.59 \mathrm{eV}$ ) or nanoLED sources (Eexc 1/4 $3.66 \mathrm{eV}$ and $2.74 \mathrm{eV}$ ) (both IBH Scotland) with pulse durations around $1 \mathrm{~ns}$. The shortest available time range was used (212.78 ns), and the corre-sponding time-per-channel was $0.208 \mathrm{~ns}$. The detection was per-formed with a photon counting TBX-04 photomultiplier module (IBH Scotland). The I(t) curves were measured for the $\mathrm{Ce}^{3 \mathrm{p}}$ - related $2.38 \mathrm{eV}$ emission. A convolution procedure (SpectraSolve software package, Ames photonics) was applied to extract true decay times using the multiexponential approximation.

The photoluminescence characteristics were measured with the use of nitrogen cryostats.

The X-ray excited luminescence and afterglow spectra were measured at 9 $\mathrm{K}$ after a crystal was irradiated with the X-ray tube $(40 \mathrm{kV}, 15 \mathrm{~mA})$ for 10 min to achieve the intensity saturation. The luminescence was detected using Andor Shamrock B-303i spec-trograph coupled with Andor DU-401A-BV CCD camera. In addi-tion, HAMAMATSU $\mathrm{H} 2859$ photomultiplier tube was used to gain extra sensitivity.

Thermally stimulated luminescence glow curves ITSL(T) were measured with a heating rate of $0.2 \mathrm{~K} / \mathrm{s}$ at two different setups. At the first setup, the TSL glow curves were measured in the $90 \mathrm{e} 500 \mathrm{~K}$ temperature range after selective UV irradiation of the crystals at different temperatures $T_{\text {irr }}$ with different irradiation photon en-ergies Eirr. A crystal located in a nitrogen cryostat was irradiated with the LOT - ORIEL xenon lamp $(150 \mathrm{~W})$ through a mono-chromator SF-4. The spectral width of the monochromator slit did not exceed $5 \mathrm{~nm}$. The TSL glow curves were measured with the monochromator SPM-1 and detected with the photomultiplier 


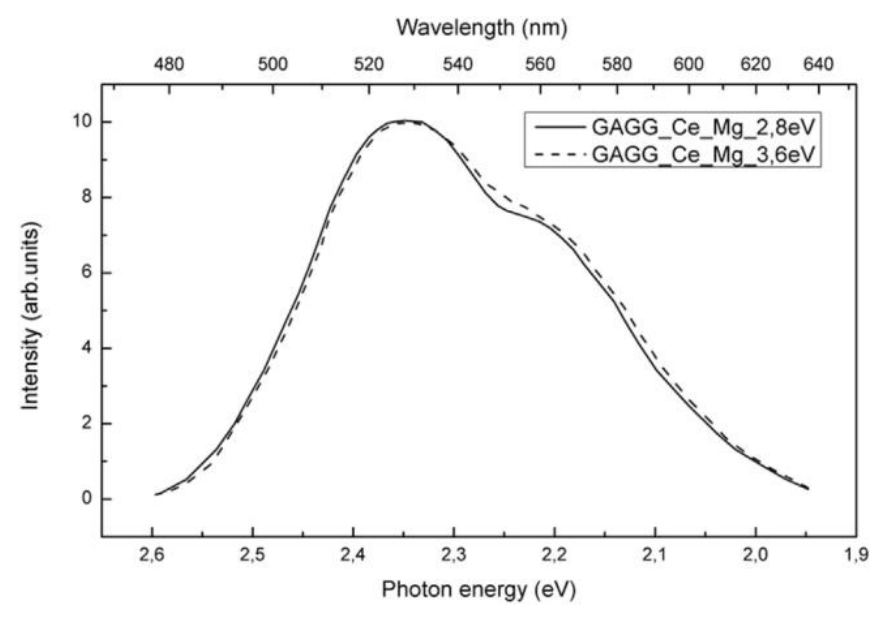

Fig. 1. Uncorrected emission spectra of GAGG:Ce, $\mathrm{Mg}$ measured at $85 \mathrm{~K}$ under excita-tion in the $\mathrm{Ce}^{3 \mathrm{p}}$ - related $4 \mathrm{f}$ e $5 \mathrm{~d}_{1}\left(2.8 \mathrm{eV}\right.$; solid line) and $4 \mathrm{f}$ e $5 \mathrm{~d}_{2}(3.6 \mathrm{eV}$; dashed line) absorption bands. The spectral width of the monochromator slits was $3.5 \mathrm{~nm}$.

FEU-39 and recorder. For each TSL glow curve peak, the TSL peak creation spectrum, i.e., the dependence of the maximum TSL in-tensity ( ${ }^{\max }$ TSL) on the irradiation photon energy Eirr, was measured. From the dependence of the maximum TSL intensity ( ${ }^{\text {max }}$ TSL) on the irradiation temperature Tirr, the activation energy $E_{a}$ for the TSL peak creation was determined. To determine the trap depth Et corresponding to each TSL peak, the partial cleaning method was used (for more details, see, e.g. [31], and references therein). The crystal, irradiated at the temperature $\mathrm{T}_{\text {irr }}$, was cooled down to $90 \mathrm{~K}$, heated up to a temperature $\mathrm{T}_{\text {stop, }}$, then quickly cooled down to $90 \mathrm{~K}$ and the TSL glow curve was recorded. In the next cycle, the same procedure was repeated for the

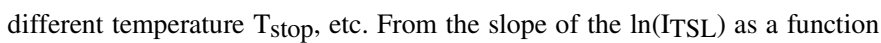
of the reverse temper-ature $(1 / \mathrm{T})$, the $\mathrm{E}_{\mathrm{t}}$ value was calculated.

At the second setup, the TSL glow curves were measured in the $9 \mathrm{e} 300 \mathrm{~K}$ temperature range after $\mathrm{X}$-ray irradiation of the crystals with the $\mathrm{X}$-ray tube $(40 \mathrm{kV}, 15 \mathrm{~mA})$ for $15 \mathrm{~min}$. The luminescence was detected using Andor Shamrock B-303i spectrograph coupled to Andor DU-401A-BV CCD camera. In addition, HAMAMATSU H2859 photomultiplier tube was used to gain extra sensitivity. Trap depths were determined using fractional glow technique [32].

\section{Experimental results and discussion}

As mentioned above, co-doping of various $\mathrm{Ce}$ - doped materials with divalent ions $\left(\mathrm{M}^{2} \mathrm{p}\right)$ results in the change of cerium valence state from $\mathrm{Ce}^{3} \mathrm{p}$ to $\mathrm{Ce}^{4 \mathrm{p}}$. For the local excess charge and volume compensation, the formation of $\mathrm{Ce}^{4 \mathrm{p}}$ and $\mathrm{M}^{2 \mathrm{p}}$ pairs can be possible in some materials. For example, the presence of the $\left\{\mathrm{Ce}^{4} \mathrm{p}-\mathrm{Pb}^{2 \mathrm{p}}\right\}$ centers in the lead-containing $\mathrm{Y}_{2} \mathrm{SiO}_{5}$ :Ce and $\mathrm{Lu}_{2} \mathrm{SiO}_{5}$ :Ce epitaxial films was found in Ref. [28]. The formation of such centers could influence the luminescence characteristics of the material, in particular, the characteristics of the electron recombination lumi-nescence (ERL) which could arise from the recombination of elec-trons with single $C e^{4 p}$ ions and with the $\left\{C e^{4 p}-M^{2} p\right\}$ centers. This effect could appear in the shift of the luminescence spectrum and in the change of the decay kinetics and temperature dependence of the luminescence intensity in the $\mathrm{M}^{2 \mathrm{p}}$ codoped materials as compared to the $\mathrm{M}^{2 \mathrm{p}}$ free ones. We have also suggested that the difference in the activation energies of the luminescence thermal quenching reported in Ref. [14] can be explained by the fact that the X-ray excited ERL arises in these crystals from the recombination of electrons with different $\mathrm{Ce}^{4 p}$ - type centers: with single $\mathrm{Ce}^{4 p}$ centers in GAGG:Ce but with both the $\mathrm{Ce}^{4 p}$ and the $\left\{\mathrm{Ce}^{4 p}-\mathrm{Ca}^{2} \mathrm{p}\right\}$ centers, in GAGG:Ce,Ca. Indeed, in the GAGG:Ce, Ca crystal with the largest ( 0.4 at. $\%) \mathrm{Ca}$ concentration, practically all $\mathrm{Ce}$ ions are in a tetravalent form [14] and, owing to a large $\mathrm{Ca}^{2 \mathrm{p}}$ content, the number of the $\left\{\mathrm{Ce}^{4 \mathrm{p}}-\mathrm{Ca}^{2 \mathrm{p}}\right\}$ pairs could be noticeable. In this case, the difference in the activation energies reported in Ref. [14] could be caused by different energy distances between the conduction band and the relaxed $5 \mathrm{~d}_{1}$ state of $\mathrm{Ce}^{3 \mathrm{p}}$ and $\left\{\mathrm{Ce}^{3 \mathrm{p}}-\mathrm{Ca}^{2 \mathrm{p}}\right\}$ centers,

indicating a noticeable influence of $\mathrm{Ca}^{2} \mathrm{p}$ on the energy levels of $\mathrm{Ce}^{3 p}$.

According to [30], the co-doping of $\mathrm{Lu}_{3} \mathrm{Al}_{5} \mathrm{O}_{12}$ : $\mathrm{Ce}$ with $\mathrm{Mg}^{2} \mathrm{p}$ stimulates the formation of paramagnetic $\mathrm{O}$ - type hole centers. We have suggested that the same effect could take place also in GAGG:Ce,Mg. In principle, the recombination of electrons with the $\mathrm{Mg}^{2} \mathrm{p}$ - stabilized $\mathrm{O}$ hole centers could result in the appearance of the localized exciton luminescence (similar to that observed, e.g., in $\mathrm{Y}_{2} \mathrm{SiO}_{5}$ :Ce and $\mathrm{Lu}_{2} \mathrm{SiO}_{5}$ :Ce crystals [37]).

Taking into account the above-mentioned data, we tried to detect the above-mentioned exciton luminescence as well as the presence of $\mathrm{Ce}^{3 \mathrm{p}}$ or $\mathrm{Ce}^{4} \mathrm{p}$ ions perturbed by $\mathrm{Mg}^{2} \mathrm{p}$ ions in the GAGG:Ce, Mg crystal. For that, we carefully compared the low-temperature emission and excitation spectra, the luminescence decay kinetics, as well as the temperature dependences of the luminescence intensity and decay times measured for the GAGG:Ce and GAGG:Ce,Mg single crystals under photoexcitation in the $\mathrm{Ce}^{3 p}$ - related absorption bands. We also compared the photo-luminescence characteristics of GAGG:Ce, Mg measured at $90 \mathrm{~K}$ under excitation in the $4 \mathrm{f}-5 \mathrm{~d}_{1}$ band of $\mathrm{Ce}^{3 p}$, where only the intra-centre $\mathrm{Ce}^{3 p}$ emission can be excited, and under excitation in the $4 \mathrm{f}$ e $5 \mathrm{~d}_{2}$ band, where the ERL could also appear due to the recombi-nation of electrons, optically released to the conduction band, with the $\mathrm{Ce}^{4 p},\left\{\mathrm{Ce}^{4 \mathrm{p}}-\mathrm{Mg}^{2} \mathrm{p}\right\}$, and $\left\{\mathrm{O}-\mathrm{Mg}^{2 \mathrm{p}}\right\}$ - type hole centers. Be-sides, the characteristics of the ERL of GAGG:Ce and GAGG:Ce,Mg have been compared also under X-ray excitation of the investigated crystals at $9 \mathrm{~K}$.

\subsection{Photoluminescence of GAGG:Ce and GAGG:Ce,Mg}

No noticeable difference was found in the photoluminescence spectra of the GAGG:Ce and GAGG:Ce,Mg crystals measured with very narrow slits. A small $(\mathrm{z} 0.01 \mathrm{eV})$ lower-energy shift of the GAGG:Ce, $\mathrm{Mg}$ spectrum with respect to the GAGG:Ce spectrum can

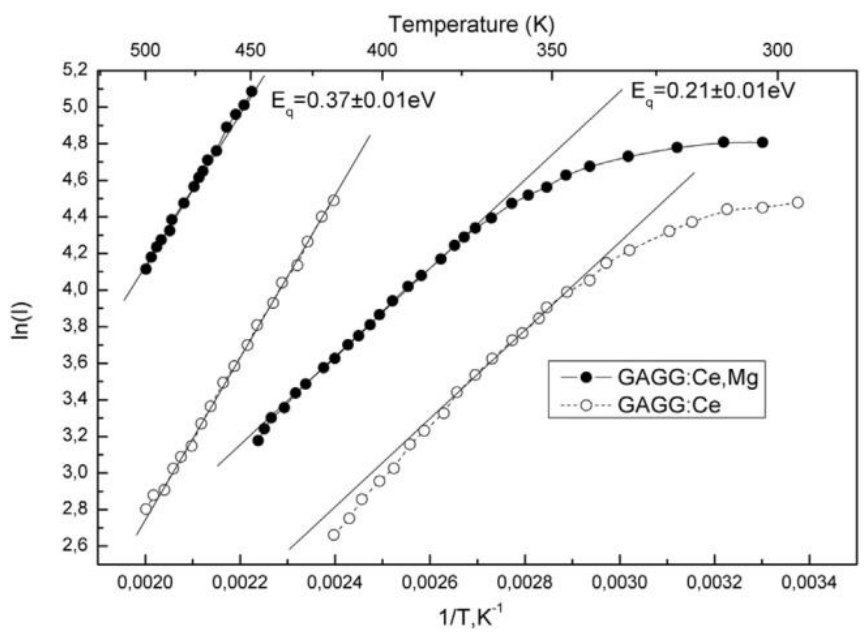

Fig. 2. The $\ln I$ e $1 / \mathrm{T}$ dependences presented for the GAGG:Ce (open circles) and GAGG:Ce, Mg (filled circles) single crystals under excitation in the $\mathrm{Ce}^{3 \mathrm{p}}-$ related $4 \mathrm{f}-5 \mathrm{~d} 1$ absorption band. 

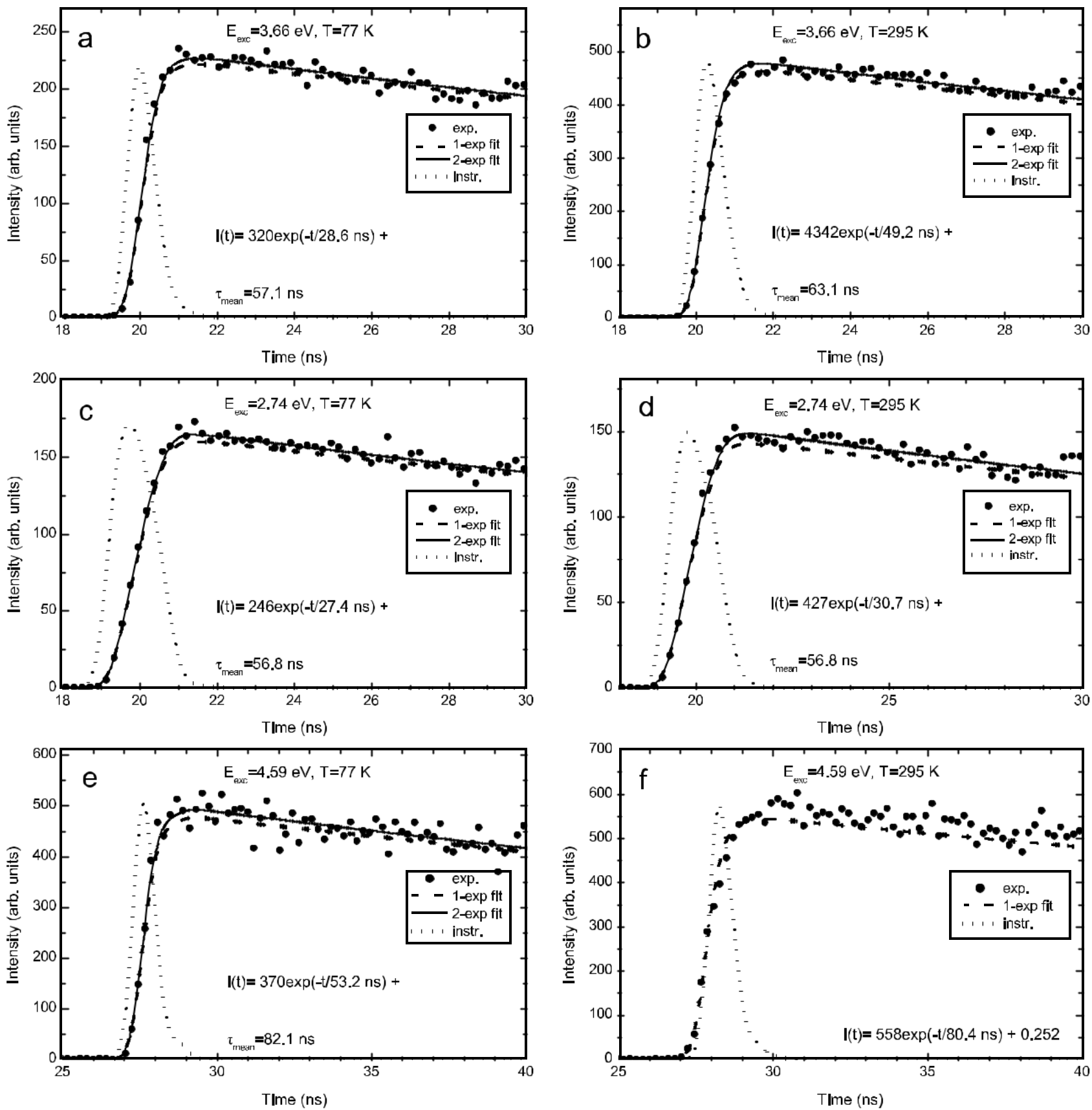

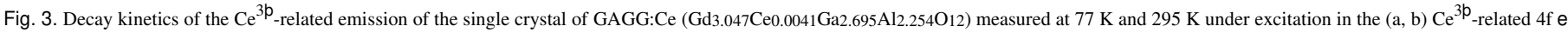
$5 \mathrm{~d}_{2}\left(\mathrm{Eexc}_{\mathrm{ex}} 1 / 43.66 \mathrm{eV}\right)$ and $(\mathrm{c}, \mathrm{d}) 4 \mathrm{f}$ e $5 \mathrm{~d}_{1}\left(\mathrm{Eexc}_{\mathrm{ex}}^{1 / 4} 2.74 \mathrm{eV}\right)$ absorption bands and $(\mathrm{e}, \mathrm{f})$ in the $\mathrm{Gd}^{3 \mathrm{p}}$-related absorption band $\left(\mathrm{E}_{\text {exc }}{ }^{1 / 4} 4.59 \mathrm{eV}\right)$.

be caused by a smaller Ga content in this crystal, see Refs. [6,24]. No noticeable difference was found in the photoluminescence spectra of GAGG:Ce,Mg measured under the $4 \mathrm{f}$ e $5 \mathrm{~d}_{1}$ and $4 \mathrm{f}$ e $5 \mathrm{~d}_{2}$ excita-tions (Fig. 1).

No noticeable difference was also observed in the temperature dependences of the $5 \mathrm{~d}_{1}$ e $4 \mathrm{f}$ luminescence intensity measured for GAGG:Ce and GAGG:Ce,Mg (Fig. 2). At the temperatures $\mathrm{T}<280 \mathrm{~K}$, the emission intensity is slightly decreasing due to the decreasing probability of the $4 \mathrm{f}$ $5 \mathrm{~d}_{1}$ absorption transitions. At higher tem-peratures, the intensity decrease with the activation energies $\mathrm{E}_{\mathrm{q}} 1 / 40.20 \mathrm{e} 0.22 \mathrm{eV}$ and $\mathrm{E}_{\mathrm{q}} \mathrm{z} 0.37 \pm 0.02 \mathrm{eV}$ is observed in the $350 \mathrm{e} 400 \mathrm{~K}$ and $400 \mathrm{e} 500 \mathrm{~K}$ temperature ranges, respectively. As it will be shown in Section 3.3, the former decrease is caused by the thermally stimulated release of electrons from the $5 \mathrm{~d}_{1}$ level of $\mathrm{Ce}^{3 \mathrm{p}}$ into the conduction band (the $\mathrm{Ce}^{3 \mathrm{p}}$ ionization). The latter decrease should be caused by some other process. In the GAGG:Ce epitaxial film of approximately the same composition (5LGB5), the activation energy of the luminescence thermal quenching in the $400 \mathrm{e} 500 \mathrm{~K}$ temperature range has been found to be $\mathrm{E}_{\mathrm{q}} 1 / 40.56 \mathrm{eV}$ [23]. There-fore, much smaller activation energy $\mathrm{E}_{\mathrm{q}} \mathrm{z} 0.37 \pm$ $0.02 \mathrm{eV}$ obtained for the same temperature range in the GAGG:Ce and GAGG:Ce,Mg single crystals cannot arise from the nonradiative $5 \mathrm{~d}_{1}$ e $4 \mathrm{f}$ transi-tions of $\mathrm{Ce}^{3 \mathrm{p}}$ ions but should be caused by some other, defect-related, process which is strongly suppressed in the epitaxial film. The activation energy values of $0.36 \mathrm{eV}$ and $0.42 \mathrm{eV}$ reported for GAGG:Ce in Refs. [33] and [5], respectively, and obtained from the 

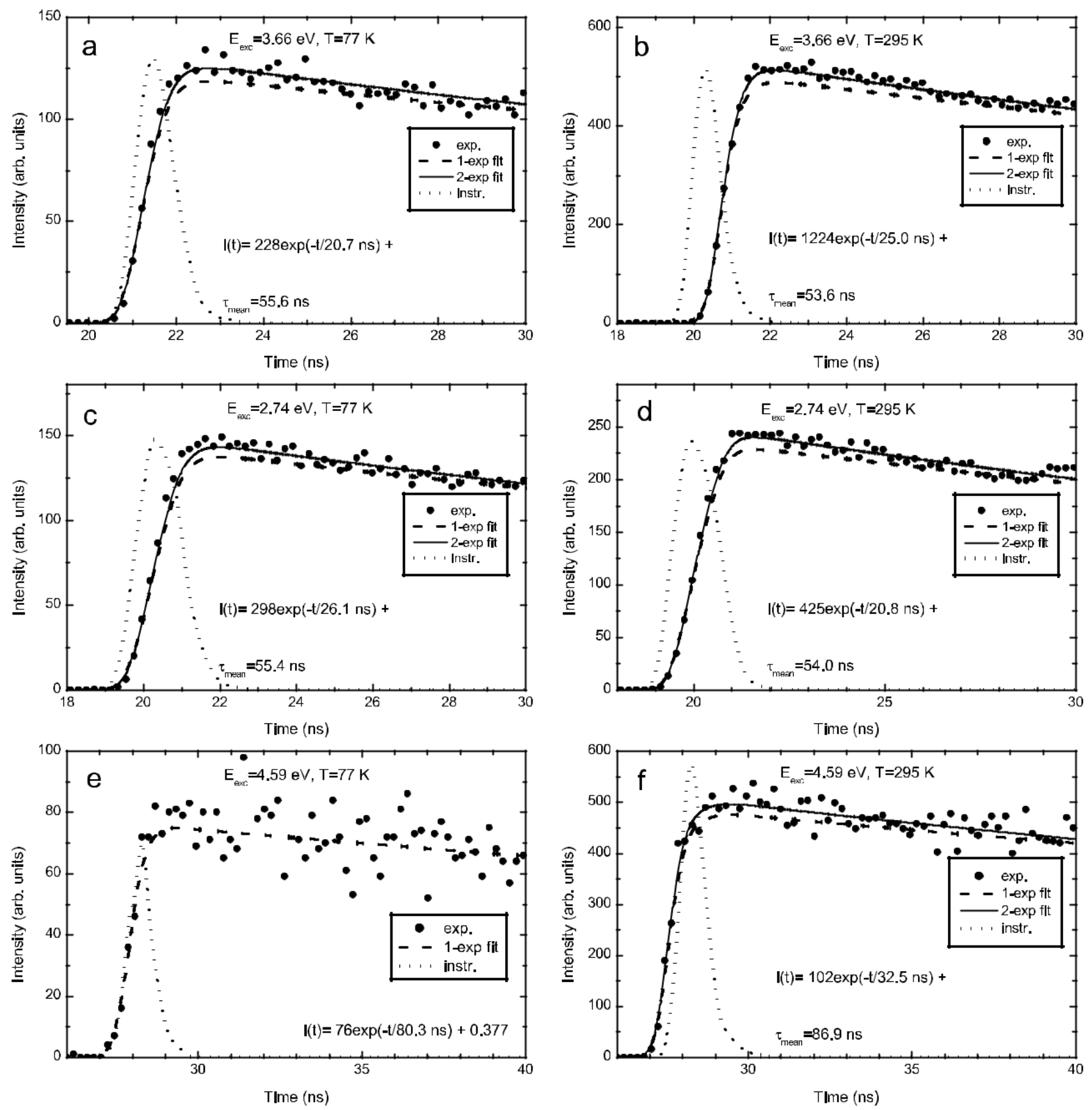

Fig. 4. Decay kinetics of the $\mathrm{Ce}^{3 \mathrm{p}}$-related emission of the single crystal of GAGG:Ce,Mg (Gd3.011Ce0.0044Mg0.0021Ga2.644Al2.339O12) obtained at $77 \mathrm{~K}$ and $295 \mathrm{~K}$ under excitation in the (a, b) $\mathrm{Ce}^{3 \mathrm{p}}$-related $4 \mathrm{f}$ e $5 \mathrm{~d}_{2}\left(\mathrm{Eexc}^{1 / 4} 3.66 \mathrm{eV}\right)$ and $(\mathrm{c}, \mathrm{d}) 4 \mathrm{f}$ e $5 \mathrm{~d}_{1}\left(\mathrm{E}_{\text {exc }} 1 / 42.74 \mathrm{eV}\right)$ absorption bands and $(\mathrm{e}, \mathrm{f})$ in the Gd ${ }^{3 \mathrm{p}}$-related absorption band $\left(\mathrm{Eexc}^{1 / 4} 4.59 \mathrm{eV}\right)$.

temperature dependences of the emission intensity and decay time, might be characteristic just for the latter process but not for the $\mathrm{Ce}^{3 \mathrm{p}}$ ionization. These data confirm the conclusion made in Ref. [23]: the true activation energy ( $\left.\mathrm{E}_{\mathrm{a}}\right)$ value for the thermally stimulated $5 \mathrm{~d}_{1}$ e CB transitions can be obtained only from the studies of the defects creation processes under irradiation of the crystal in the $C e^{3 p}$ - related $4 \mathrm{f}-5 \mathrm{~d}_{1}$ or $4 \mathrm{f}-5 \mathrm{~d}_{2}$ absorption bands. Besides, since the $\mathrm{E}_{\mathrm{a}}$ value strongly depends on the Ga content in the multicomponent garnets [23], another reason of large $\mathrm{E}_{\mathrm{q}}$ values obtained in Refs. [5,33] can be caused by smaller true Ga concen-tration in the investigated crystals (compared to the value known in the melt).

As mentioned above, the GAGG:Ce co-doping with $\mathrm{Mg}^{2 \mathrm{p}}$ results in a noticeable shortening of the scintillation decay and rise times (for more details, see Ref. [19]). Therefore, it was of interest to investigate the influence of $\mathrm{Mg}^{2 \mathrm{p}}$ on the photoluminescence decay kinetics of GAGG:Ce. In Figs. 3 and 4 , the initial parts of the decay curves $\mathrm{I}(\mathrm{t})$ of the $\mathrm{Ce}^{3 \mathrm{p}}$ - related emission of GAGG:Ce and GAGG:-Ce,Mg single crystals measured at different experimental condi-tions (shown in the legends) are presented. For comparison, the initial parts of the decay curves obtained for the GAGG:Ce epitaxial film are also shown in Fig. 5. The fits of an experimental decay curve with one or two exponential components are shown by lines. In case of the two-exponential approximation, instead of the decay time $t$, the mean time $t_{\text {mean }}$ is used defined by the equation [34]: 

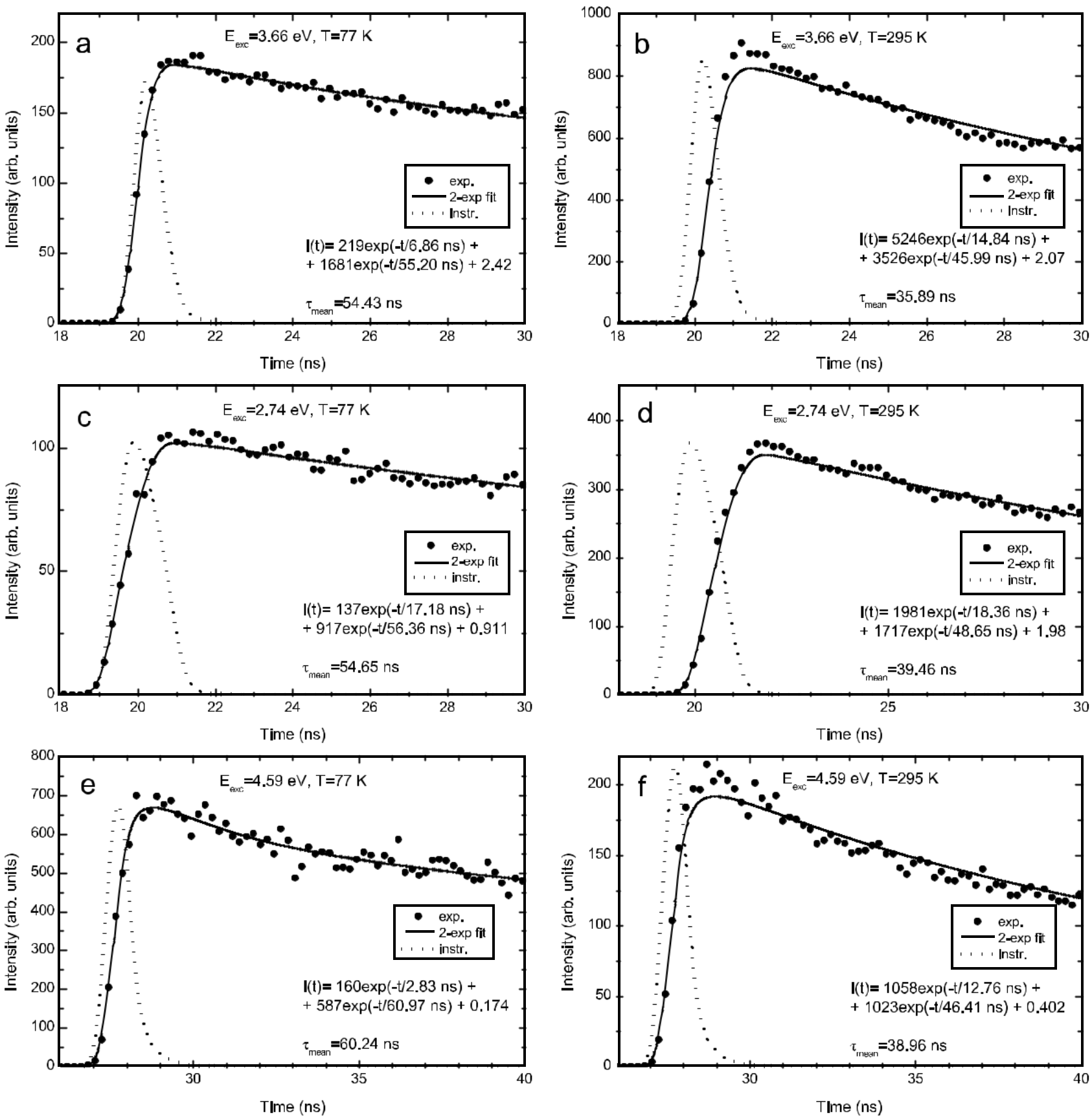

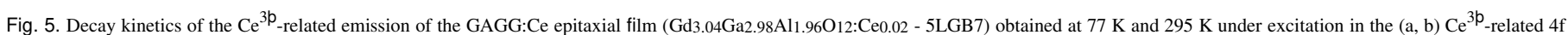
e $5 d_{2}\left(E_{\text {exc }} 1 / 43.66 \mathrm{eV}\right)$ and $(c, d) 4 f$ e $5 d_{1}\left(E_{\text {exc }} 1 / 42.74 \mathrm{eV}\right)$ absorption bands and $(e, f)$ in the $\mathrm{Gd}^{3 \mathrm{p}}$-related absorption band $\left(\mathrm{E}_{\text {exc }}{ }^{1 / 4} 4.59 \mathrm{eV}\right)$.

Table 1

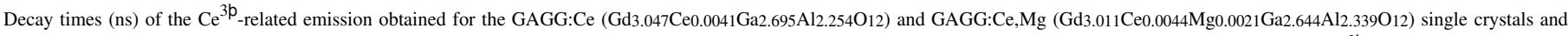

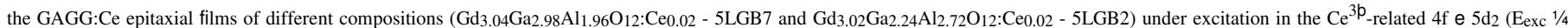

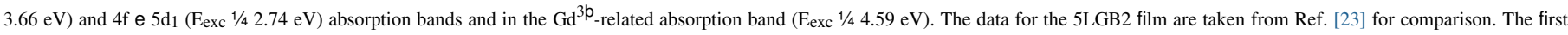
number is the decay time obtained in the 1-exponential approximation and the second number is the mean time ( $t_{\text {mean }}$ ) obtained in the 2-exponential approximation, see Figs. $3 e 5$.

\begin{tabular}{|c|c|c|c|c|c|c|}
\hline \multirow[t]{2}{*}{ Sample/Eexc } & \multicolumn{3}{|l|}{$\mathrm{T} 1 / 477 \mathrm{~K}$} & \multicolumn{3}{|l|}{$\mathrm{T} 1 / 4295 \mathrm{~K}$} \\
\hline & $3.66 \mathrm{eV}$ & $2.74 \mathrm{eV}$ & $4.59 \mathrm{eV}$ & $3.66 \mathrm{eV}$ & $2.74 \mathrm{eV}$ & $4.59 \mathrm{eV}$ \\
\hline GAGG:Ce & $56.3 ; 57.1$ & $56.0 ; 56.8$ & $69.8 ; 82.1$ & $56.9 ; 63.1$ & $55.2 ; 56.8$ & 80.4 \\
\hline GAGG:Ce,Mg & $54.4 ; 55.6$ & $54.3 ; 55.4$ & 80.3 & $52.3 ; 53.6$ & $53.1 ; 54.0$ & $82.2 ; 86.9$ \\
\hline 5LGB7 film & 54.4 & 54.7 & 60.2 & 35.9 & 39.5 & 39.0 \\
\hline 5LGB2 flm & 55.8 & 56.0 & 64.4 & 44.6 & 48.0 & 51.7 \\
\hline
\end{tabular}



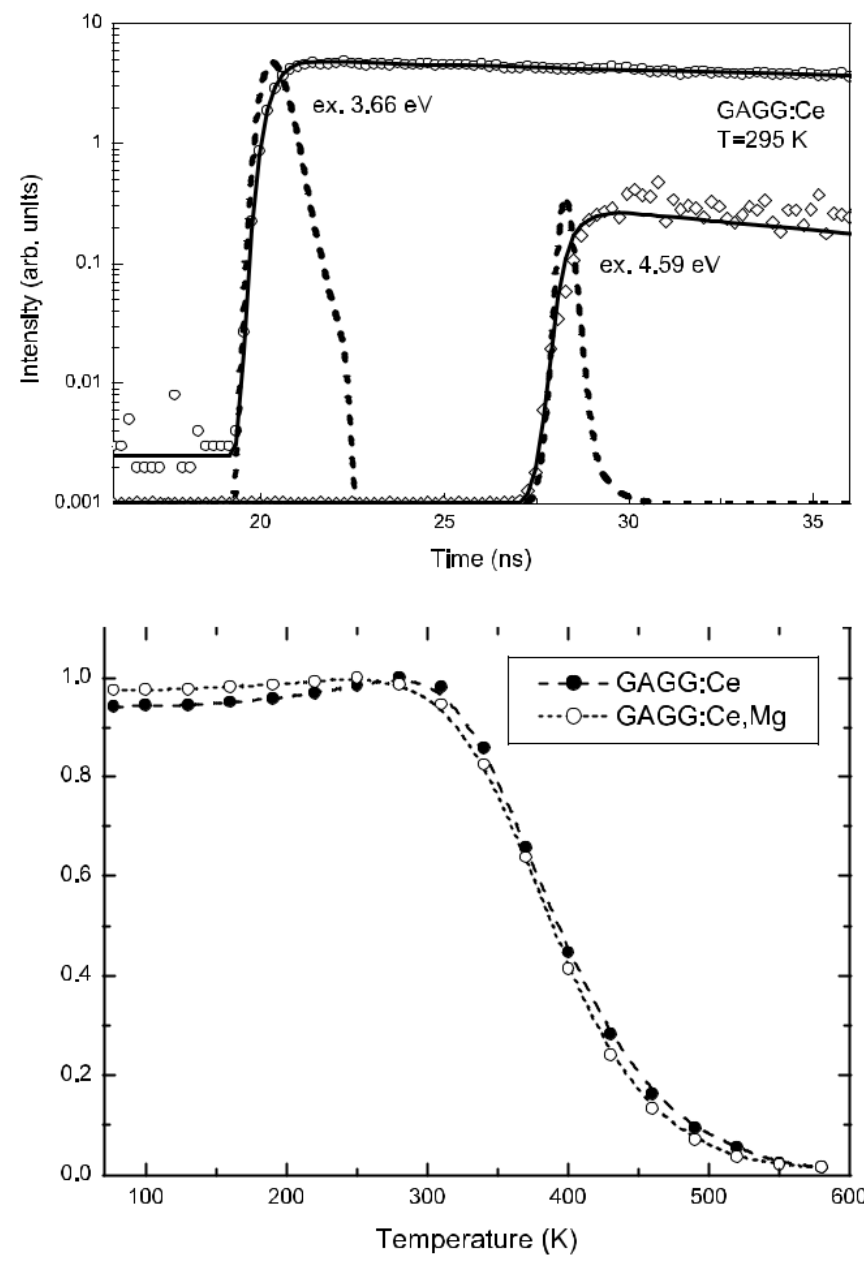

Fig. 6. (a) Initial part of the photoluminescence decay curves measured at $295 \mathrm{~K}$ for the visible $\mathrm{Ce}^{3 \mathrm{p}}$ emission of the GAGG:Ce single crystal under excitation in the $4 \mathrm{f}$ e $5 \mathrm{~d}_{2}\left(\mathrm{E}_{\mathrm{exc}} \mathrm{1}_{4} 3.66 \mathrm{eV}\right)$ absorption band of $\mathrm{Ce}^{3 \mathrm{p}}$ and in the $\mathrm{Gd}^{3 \mathrm{p}}$ - related absorption band; Eexc $1 / 44.59 \mathrm{eV}$. (b) Normalized temperature dependences of the luminescence decay times measured under excitation in the $\mathrm{Ce}^{3 \mathrm{p}}$ - related $4 \mathrm{f}$ e $5 \mathrm{~d} 1$ absorption band of GAGG:Ce (filled circles) and GAGG:Ce,Mg (empty circles); Eexc $1 / 42.72 \mathrm{eV}$.

$$
\operatorname{tmean}_{1 / 4 \mathrm{X}} \mathrm{X}^{\mathrm{Ait}_{\mathrm{i}}{ }^{2 \cdot}}
$$

where $t_{i}$ are the decay times of the single-exponential components and $A_{i}$ are the corresponding initial intensities. The $t$ and $t_{\text {mean }}$ values are presented in Table 1.

The analysis of the obtained data has shown that all the $I(t)$ curves presented in Figs. $3 e 5$ are similar. The coinciding decay curves are observed even under excitation in the $4 \mathrm{f}-5 \mathrm{~d}_{2}$ absorption band, where the ionization of $\mathrm{Ce}^{3 \mathrm{p}}$ takes place and electron and hole centers are created, and under excitation at $77 \mathrm{~K}$ in the $4 \mathrm{f}-5 \mathrm{~d}_{1}$ absorption band (Fig. $3 \mathrm{c}$ and Fig. $5 \mathrm{c}$ ), where no ionization is possible. In the latter case, only the intra-centre luminescence of $\mathrm{Ce}^{3 \mathrm{p}}$ is excited. In all the samples studied, no prominent photoluminescence intensity rise is observed under all considered exci-tation conditions. It should be especially noted that, unlike in the scintillation decay [19], no noticeable intensity rise is observed even for the single crystal of GAGG:Ce. As an example, the initial parts of the $\mathrm{I}(\mathrm{t})$ curves, measured for this crystal at $295 \mathrm{~K}$ under excitation in the $4 \mathrm{f}-5 \mathrm{~d}_{2}$ absorption band of $\mathrm{Ce}^{3 \mathrm{p}}$ and in the $\mathrm{Gd}^{3 \mathrm{p}}$ - related band, are demonstrated in more detail in Fig. 6a. However, in case the rise time value is below 1 nanosecond, its observation

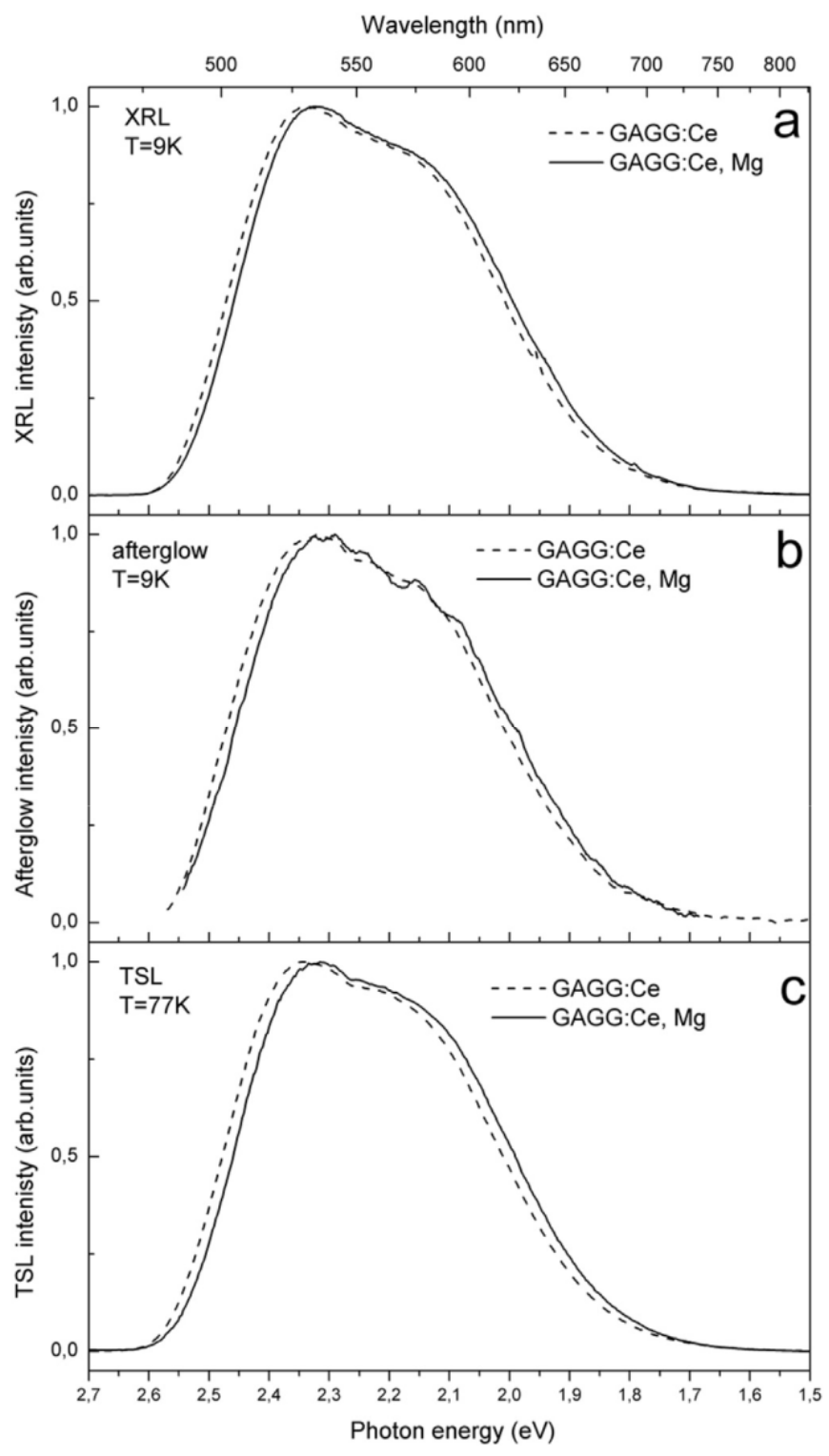

Fig. 7. Corrected spectra of the (a) X-ray excited luminescence, (b) afterglow, and (c) thermally stimulated luminescence measured at the same conditions for the GAGG:-

$\mathrm{Ce}, \mathrm{Mg}$ (solid line) and GAGG:Ce (dashed line) crystals. The spectral width of the monochromator slits was 1.1

could be hampered by the time resolution limits of our experiment. Temperature dependences of the luminescence decay times in the GAGG:Ce and GAGG:Ce,Mg crystals are also practically coin-ciding (Fig. 6b).

Similarly to the temperature dependences of the emission intensity (Fig. 2), two exponential stages with the acti-vation energies around $0.21 \mathrm{eV}$ and 0.37 $\mathrm{eV}$ can be separated in the $360 \mathrm{e} 410 \mathrm{~K}$ and $450 \mathrm{e} 520 \mathrm{~K}$ temperature ranges.

The comparison of the data obtained for the single crystals of GAGG:Ce and GAGG:Ce,Mg under excitation in the $4 \mathrm{f}-5 \mathrm{~d}$ absorp-tion bands of $\mathrm{Ce}^{3 p}$ allows us to conclude that, unlike in the scin-tillation decay [19], the influence of $\mathrm{Mg}$ co-doping on the decay kinetics of the $\mathrm{Ce}^{3 \mathrm{p}}$ - related photoluminescence is negligible (see Figs. 3 and 4 and Table 1).

Relatively short decay times observed at $295 \mathrm{~K}$ for the 5LGB7 film (Fig. 5) are caused by relatively large Ga content in this film. Due to that, the thermal quenching of the $\mathrm{Ce}^{3} \mathrm{p}$ - related emission caused by the $\mathrm{Ce}^{3 \mathrm{p}}$ ionization takes place at lower temperatures 

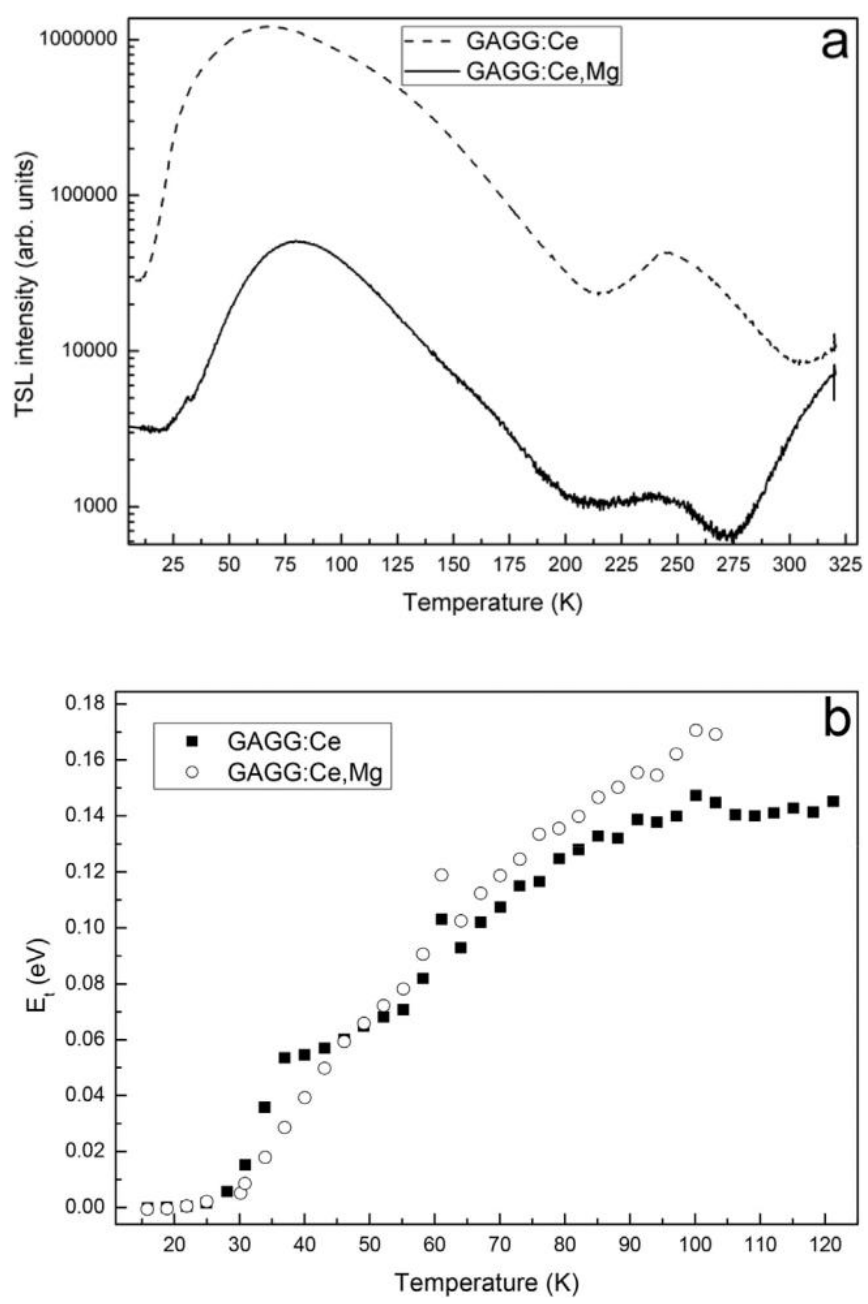

Fig. 8. (a) TSL glow curves of the X-ray irradiated at $9 \mathrm{~K}$ GAGG:Ce, $\mathrm{Mg}$ (solid line) and GAGG:Ce (dashed line) single crystals measured at the same conditions in the $9 e 300 \mathrm{~K}$ temperature range. (b) Trap depths for the $9 \mathrm{e} 125 \mathrm{~K}$ temperature range acquired using fractional glow technique.

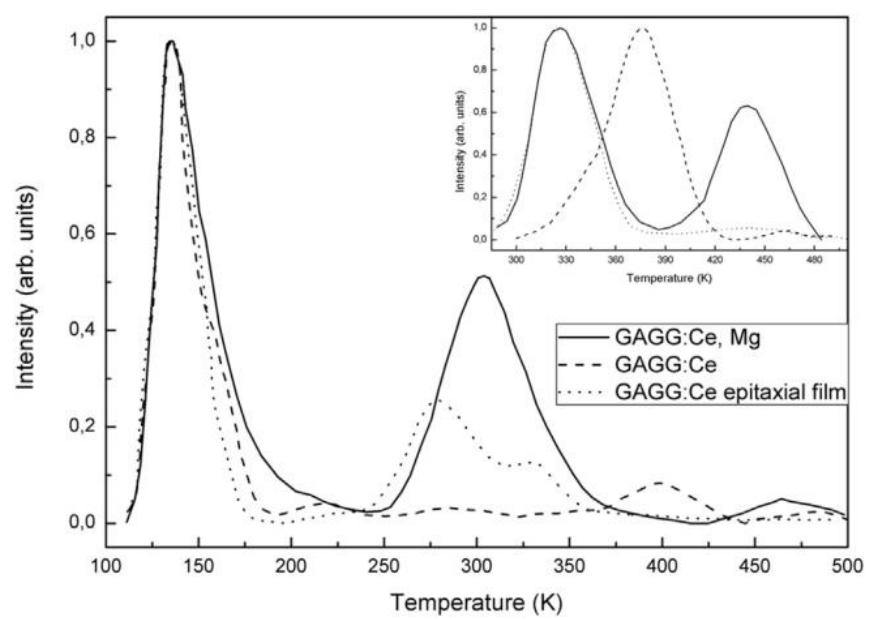

Fig. 9. TSL glow curves (normalized at $114 \mathrm{~K}$ ) measured in the $90 \mathrm{e} 500 \mathrm{~K}$ temperature range for the GAGG:Ce, $\mathrm{Mg}$ (solid line) and GAGG:Ce (dashed line) single crystals and the GAGG:Ce epitaxial film (dotted line) irradiated at $85 \mathrm{~K}$ in the $\mathrm{Ce}^{3 \mathrm{p}}$ - related $4 \mathrm{f}$ e $5 \mathrm{~d}_{2}$ absorption band $(3.6 \mathrm{eV})$. In the inset, the TSL glow curves (normalized at maximum intensity) measured after irradiation of the same samples at $295 \mathrm{~K}$ in the $\mathrm{Ce}^{3 \mathrm{p}}$ - related $4 \mathrm{f}$ e $5 \mathrm{~d}_{1}$ absorption band $(2.75 \mathrm{eV})$
[24].

Under excitation in the $\mathrm{Gd}^{3 \mathrm{p}}$ - related absorption band (Eexc $\left.1 / 44.59 \mathrm{eV}\right)$, the expected slower decay kinetics of the $\mathrm{Ce}^{3 \mathrm{p}}$ emission is observed, which is caused by the effective $\mathrm{Gd}^{3 \mathrm{p}}-\mathrm{Ce}^{3 \mathrm{p}}$ energy transfer processes (for more details, see Ref. [35]).

\subsection{X-ray excited luminescence of GAGG:Ce and GAGG:Ce,Mg}

The X-ray excited luminescence spectra measured at $9 \mathrm{~K}$ with the narrow slits indicate that the $\mathrm{Ce}^{3 \mathrm{p}}$ - related emission band in GAGG:Ce,Mg is slightly shifted to lower energy as compared to GAGG:Ce (Fig. 7a). The same small shift is also observed in the afterglow spectra (Fig. 7b) and in the TSL spectra (Fig. 7c) of these crystals. In principle, this shift could be caused by the presence of $\mathrm{Ce}^{4 \mathrm{p}}$ ions perturbed by $\mathrm{Mg}^{2} \mathrm{p}$ ions in GAGG:Ce,Mg. However, most probably, the low-energy shift can be explained by smaller Ga content in GAGG:Ce,Mg (x 1/4 2.69) as compared with GAGG:Ce (x 1/4 2.83) (see, e.g., $[6,24])$.

The intensity of the X-ray excited luminescence in the GAGG:-Ce,Mg crystal is about 1.6 times weaker as compared with the GAGG:Ce crystal.

In the X-ray excited ERL spectrum of GAGG:Ce,Mg, no additional band, which could arise from the recombination of electrons with the $\mathrm{Mg}^{2} \mathrm{p}$. stabilized hole $\mathrm{O}$ centers, was found. Most probably, the electron recombinations with these hole centers are non-radiative.

\subsection{Thermally stimulated luminescence of GAGG:Ce and GAGG:Ce,Mg}

Unlike the photo- and radioluminescence characteristics, the characteristics of thermally stimulated luminescence of GAGG:Ce and GAGG:Ce,Mg are found to be strongly different (Figs. 8 and 9). The TSL glow curves of the X-ray irradiated at 9 K GAGG:Ce, $\mathrm{Mg}$ (solid line) and GAGG:Ce (dashed line) single crystals measured at the same conditions in the $9 \mathrm{e} 300 \mathrm{~K}$ temperature range are pre-sented in Fig. 8. For GAGG:Ce, the TSL glow curve is similar to that reported in Refs. $[9,10,13]$. It is evident that the co-doping of GAGG:Ce with Mg results in the drastic decrease of the TSL in-tensity, especially in the $140 \mathrm{e} 250 \mathrm{~K}$ temperature range. In GAGG:Ce, $\mathrm{Mg}$, the total TSL intensity is by about 1 to 2 orders of magnitude weaker than that in GAGG:Ce. Both in the GAGG:Ce and GAGG:Ce,Mg crystals, the most intense is the broad complex lowest-temperature TSL peak located around 77 $\mathrm{K}$ with a shoulder around $175 \mathrm{~K}$. In all the TSL peaks, only the $\mathrm{Ce}^{3 \mathrm{p}}$-related lumi-nescence is observed (Fig. 7c). No additional emission band, which could arise from the recombination of electrons with the $\left\{\mathrm{O}-\mathrm{Mg}^{2} \mathrm{p}\right\}$ - type hole centers, was found in the TSL spectrum of GAGG:Ce,Mg.

Previous studies (see, e.g., $[14,23]$ ) have shown that the $5 \mathrm{~d} 2$ excited level of $\mathrm{Ce}^{3 \mathrm{p}}$ is located inside the conduction band of GAGG. For the $5 \mathrm{~d}_{1}$ excited level, different positions with respect to the $\mathrm{CB}$, have been reported depending on the Ga content $[5,6,14,23]$. Under UV irradiation of the crystals at $90 \mathrm{~K}$ in the $4 \mathrm{f}$ e $5 \mathrm{~d}_{2}$ absorption band of $\mathrm{Ce}^{3 \mathrm{p}}\left(\mathrm{E}_{\operatorname{exc}} 1 / 43.6 \mathrm{eV}\right)$ the electrons, optically released to the $\mathrm{CB}$, become trapped at different traps. The thermally stimulated release of the trapped electrons results in the appearance of the electron recombination luminescence. The same processes take place under irradiation at $295 \mathrm{~K}$ in the $4 \mathrm{f}-5 \mathrm{~d}_{1}$ absorption band $\left(\mathrm{E}_{\text {exc }} 1 / 42.74 \mathrm{eV}\right)$.

After UV irradiation of the investigated crystals at $90 \mathrm{~K}$ in the $4 \mathrm{f}$ e $5 \mathrm{~d}_{2}$ absorption band of $\mathrm{Ce}^{3 p}$, the afterglow is observed. Its in-tensity in GAGG:Ce,Mg is about 40 times weaker than that in GAGG:Ce.

The TSL glow curves of the GAGG:Ce,Mg (solid line) and GAGG:Ce (dashed line) single crystals irradiated in the $4 \mathrm{f}$ e $5 \mathrm{~d}_{2}$ 
Table 2

TSL characteristics of the GAGG:Ce and GAGG:Ce, Mg single crystals and the GAGG:Ce epitaxial film, see Figs. 9 and 11.

\begin{tabular}{|c|c|c|c|}
\hline TSL peak, K ( $\left.\mathrm{T}_{\text {irr }} 1 / 490 \mathrm{~K}\right)$ & Relative intensity & Trap depth, eV & Frequency factor, $\mathrm{s}^{1}$ \\
\hline \multicolumn{4}{|l|}{ GAGG:Ce crystal } \\
\hline 113 & 140 & $0.20 \pm 0.01$ & $\sim 10^{7}$ \\
\hline 150 & 8 & $0.40 \pm 0.02$ & $\sim 10^{12}$ \\
\hline 200 & 7 & $0.50 \pm 0.02$ & $\sim 10^{11}$ \\
\hline 260 & 6 & $0.62 \pm 0.02$ & $\sim 10^{10}$ \\
\hline 325 & 5 & $0.72 \pm 0.02$ & $\sim 10^{9}$ \\
\hline 380 & 13 & $0.96 \pm 0.02$ & $\sim 10^{11}$ \\
\hline 460 & $1 \mathrm{e} 2$ & e & \\
\hline \multicolumn{4}{|l|}{ TSL peak, $\mathrm{K}\left(\mathrm{T}_{\text {irr }} 1 / 4295 \mathrm{~K}\right)$} \\
\hline 325 & 7 & $0.88 \pm 0.04$ & $\sim 10^{11}$ \\
\hline 378 & 77 & $0.97 \pm 0.02$ & $\sim 10^{11}$ \\
\hline 460 & $2 \mathrm{e} 3$ & $0.75 \pm 0.05$ & $\sim 10^{6}$ \\
\hline \multicolumn{4}{|l|}{ GAGG:Ce, Mg crystal } \\
\hline 115 & 135 & $0.22 \pm 0.01$ & $\sim 10^{8}$ \\
\hline 160 & 22 & $0.43 \pm 0.02$ & $\sim 10^{12}$ \\
\hline 200 & 8 & e & \\
\hline 285 & 70 & $0.65 \pm 0.05$ & $\sim 10^{10}$ \\
\hline 325 & $\sim 20$ & $0.84 \pm 0.03$ & $\sim 10^{11}$ \\
\hline 440 & 8 & $0.95 \pm 0.02$ & $\sim 10^{9}$ \\
\hline \multicolumn{3}{|l|}{ TSL peak, $\mathrm{K}\left(\mathrm{T}_{\mathrm{irr}}\right.$ 1/4 $\left.295 \mathrm{~K}\right)$} & \multirow{3}{*}{$\begin{array}{l}10^{11} \\
10^{9}\end{array}$} \\
\hline 325 & 48 & $0.87 \pm 0.03$ & \\
\hline 440 & 31 & $0.99 \pm 0.03$ & \\
\hline \multicolumn{4}{|l|}{ GAGG:Ce film (5LGB5) } \\
\hline 114 & 141 & $0.21 \pm 0.01$ & $\sim 10^{8}$ \\
\hline 140 & 5 & $0.30 \pm 0.02$ & $\sim 10^{9}$ \\
\hline 155 & 4 & $0.42 \pm 0.02$ & $\sim 10^{12}$ \\
\hline 200 & 3.5 & e & \\
\hline 260 & 37 & $0.60 \pm 0.02$ & $\sim 10^{10}$ \\
\hline 312 & 19 & $0.66 \pm 0.04$ & $\sim 10^{9}$ \\
\hline 435 & 2 & e & \\
\hline \multicolumn{4}{|l|}{ TSL peak, K (Tirr $1 / 4295 \mathrm{~K})$} \\
\hline 327 & 49 & $0.68 \pm 0.02$ & \multirow[t]{2}{*}{$5 \quad 10^{8}$} \\
\hline 435 & 4 & e & \\
\hline
\end{tabular}

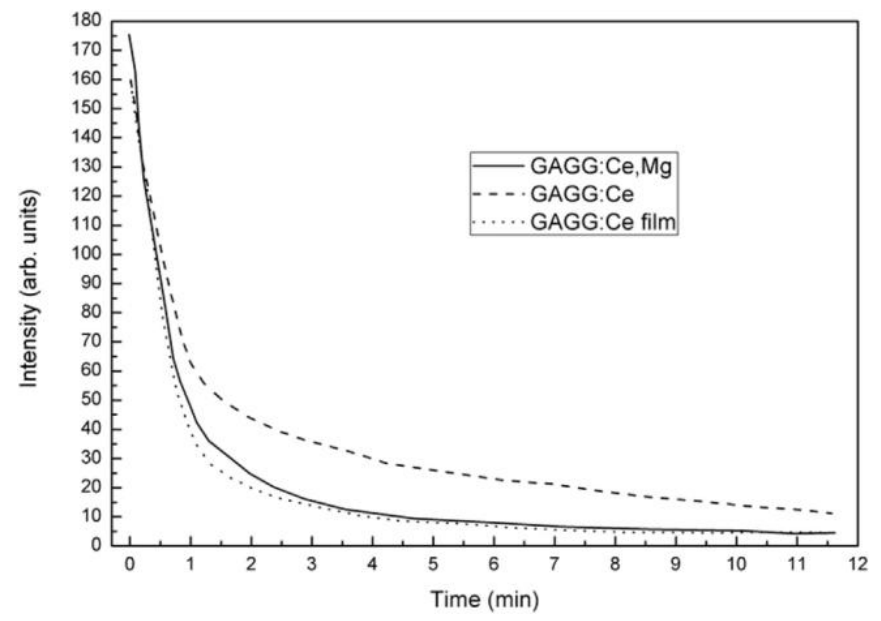

Fig. 10. Dependences of the afterglow intensity on time $t$ measured after the sample irradiation at $90 \mathrm{~K}$ with $\mathrm{E}_{\mathrm{irr}} 1 / 43.6 \mathrm{eV}$ (normalized at $\mathrm{t} 1 / 40.25 \mathrm{~min}$ ) for the GAGG:Ce,Mg (solid line) and GAGG:Ce (dashed line) single crystals and the GAGG:Ce film (dotted line).

absorption band of $\mathrm{Ce}^{3 \mathrm{p}}$ are compared in Fig. 9. After UV irradiation at $90 \mathrm{~K}$, the most intense complex TSL peak is located around $113 \mathrm{e} 115 \mathrm{~K}$ with a weaker shoulder around $150 \mathrm{e} 160 \mathrm{~K}$. In GAGG:-Ce,Mg, the intensity of this peak is about 36 times weaker as compared to GAGG:Ce. In GAGG:Ce, much weaker complex TSL peaks are observed around $200 \mathrm{~K}, 260 \mathrm{~K}, 325 \mathrm{~K}$, $380 \mathrm{~K}$, and $460 \mathrm{~K}$ (see also Table 2). In GAGG:Ce, Mg, the intensity of a new $285 \mathrm{~K}$ peak is about two times weaker as compared with the $115 \mathrm{~K}$ peak; a new peak is observed also around $440 \mathrm{~K}$. The peak of GAGG:Ce located around $380 \mathrm{~K}$ is completely absent in GAGG:Ce,Mg (see also the inset to Fig. 9).

Thus, unlike GAGG:Ce,Ca, where a new intense peak appears at $390 \mathrm{~K}$ with the intensity comparable to that of the main low-temperature TSL peak in GAGG:Ce [5], no such peak is observed in GAGG:Ce,Mg. This indicates much more favourable defect structure in GAGG:Ce, $\mathrm{Mg}$ and could be a reason of better scintil-lation characteristics of GAGG:Ce,Mg as compared with GAGG:-Ce,Ca (see Ref. [15]).

For comparison, the TSL glow curve of the GAGG:Ce epitaxial film of similar composition (5LGB5), measured in Ref. [23] after irradiation of the film in the $4 \mathrm{f}-5 \mathrm{~d}_{2}$ absorption band of $\mathrm{Ce}^{3 \mathrm{p}}$, is also presented in Fig. 9 (dotted line). It is interesting to note that the absolute values of the afterglow and the TSL intensity in the GAGG:Ce film and the GAGG:Ce,Mg crystal are comparable. The peak at about $380 \mathrm{~K}$ is absent also in the GAGG:Ce film. The after-glow decay kinetics are similar as well. Indeed, in both these samples, the afterglow decays much more quickly as compared with the GAGG:Ce single crystal (Fig. 10). These data indicate that not only the decrease of the preparation temperature but also the co-doping with $\mathrm{Mg}^{2 \mathrm{p}}$ can strongly affect the defect structure in GAGG:Ce. Similar conclusion was made in Ref. [29] on the influence of $\mathrm{Mg}^{2} \mathrm{p}$ on the defect structure in Lu3Al5O12:Ce.

From the TSL data, the parameters of the traps (trap depths $E_{t}$ and frequency factors $\mathrm{f}_{0}$ ) corresponding to each TSL can be deter-mined. In the $8 \mathrm{e} 125 \mathrm{~K}$ temperature range, the $\mathrm{E}_{\mathrm{t}}$ values are ob-tained using fractional glow technique [32], see Fig. 8b. In the $90 \mathrm{e} 500 \mathrm{~K}$ temperature range, the $\mathrm{E}_{\mathrm{t}}$ values are obtained by the partial cleaning method (for more details, see, e.g. [31], and refer-ences therein) from the slope of the $\operatorname{lnITSL}(1 / \mathrm{T})$ dependences after heating of the irradiated sample up to the selected temperatures $T_{\text {stop. }}$ In Fig. 11, the dependences of the trap depths $\mathrm{E}_{\mathrm{t}}$ on the 


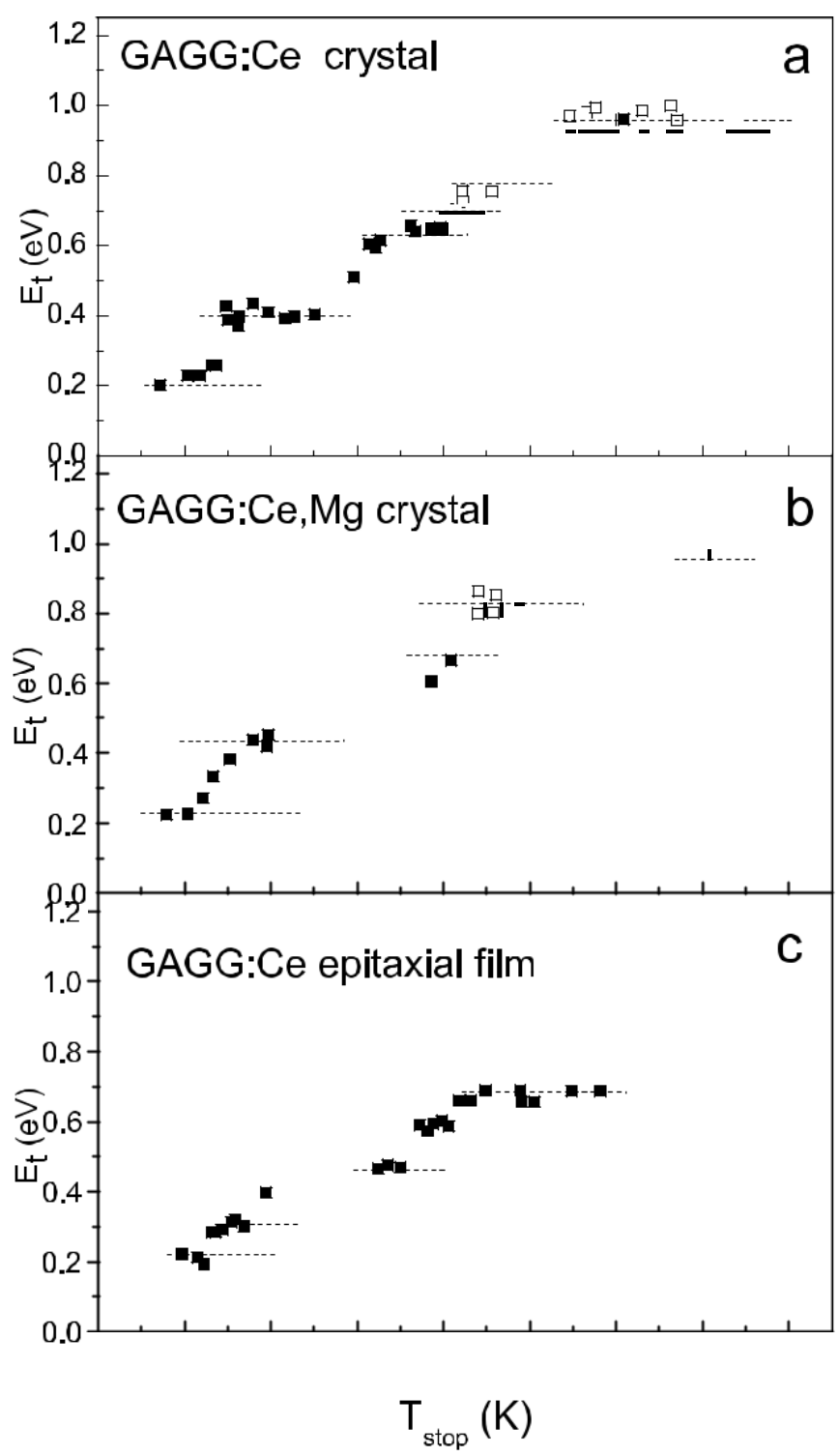

Fig. 11. Dependences of the trap depths Et, corresponding to different TSL glow curve peaks, on the temperature Tstop obtained for the (a) GAGG:Ce and (b) GAGG:Ce,Mg single crystals and (c) the GAGG:Ce epitaxial film irradiated at $90 \mathrm{~K}$ in the $4 \mathrm{f} \mathrm{e} 5 \mathrm{~d}_{2}$ absorption band of $\mathrm{Ce}^{3 \mathrm{p}}$.

temperature $\mathrm{T}_{\text {stop }}$ are presented for the GAGG:Ce and GAGG:Ce,Mg single crystals and the GAGG:Ce film (see also Table 2). In case of the first-order recombination kinetics characteristic for GAGG:Ce (see, e.g., $[9,10,13]$ ), the frequency factors $\mathrm{f}_{0}$ can be calculated using the expression

$$
f_{0} 1 / 4 b E_{t} k T_{m}^{2} \text { expðEt=kTmp; }
$$

where $\mathrm{b}$ is the crystal heating rate, $\mathrm{k}$ is the Boltzmann factor, and $\mathrm{T}_{\mathrm{m}}$ is the maximum position of the considered TSL peak. Due to a complex structure of the TSL peaks, only approximate values of the $E_{t}$ and fo parameters could be obtained. The $\mathrm{T}_{\mathrm{m}}$ value is taken as the temperature where the peak position

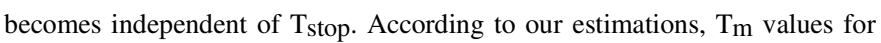
the main TSL peaks can be defined with an accuracy of about $2 \mathrm{e} 5 \mathrm{~K}$. The values of $E_{t}$ are defined with an accuracy of about $5 e 10 \%$. For the $f_{0}$ values, only an order of magnitude can be roughly estimated (Table 2).

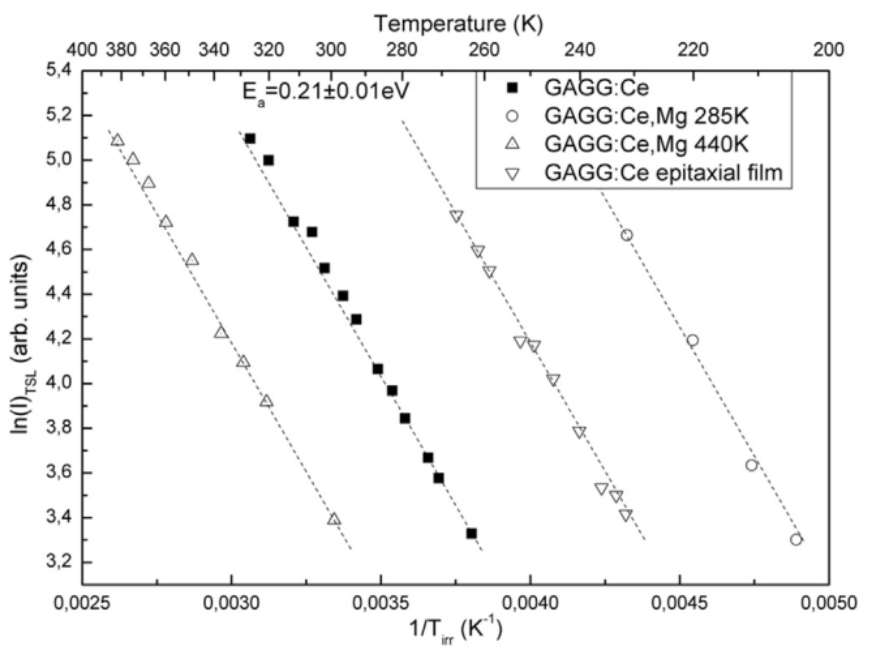

Fig. 12. The ln ITSL e $1 / T_{\text {irr }}$ dependences measured for the GAGG:Ce crystal (for the TSL peak at $380 \mathrm{~K}$ ), the GAGG:Ce,Mg crystal (for the TSL peaks at $285 \mathrm{~K}$ and $440 \mathrm{~K}$ ), and the GAGG:Ce epitaxial film (for the TSL peak at $325 \mathrm{~K}$ ) irradiated in the $\mathrm{Ce}^{3 \mathrm{p}}$ - related $4 \mathrm{f}-5 \mathrm{~d} 1$ absorption band.

It is evident, that the $E_{t}$ values for the TSL peaks located in the $\mathrm{T}<230 \mathrm{~K}$ temperature range are not much influenced by the $\mathrm{Mg}^{2 \mathrm{p}}$ co-doping and the preparation temperature of GAGG:Ce. This in-dicates the similar origin of the corresponding traps in all the samples studied. Based on presented data we suggest that the electron traps, responsible for the TSL peaks located in the $150 \mathrm{e} 230 \mathrm{~K}$ range, can be caused by the antisite defects. The com-

plex TSL peak around $285 \mathrm{~K}$, arising from the traps with $\mathrm{E}_{\mathrm{t}} \mathrm{z} 0.65 \mathrm{eV}$, is characteristic for the GAGG:Ce, Mg crystal and, most probably, arises from a $\mathrm{Mg}^{2} \mathrm{P}$ - containing defect. The lower-temperature part of this peak can arise from a hole trapped at an oxygen ion located close to a $\mathrm{Mg}^{2} \mathrm{p}$ ion (the $\{\mathrm{O}$ $\mathrm{Mg}^{2} \mathrm{p}_{3}$ - type hole centre). As it was mentioned above, these centers are detected only in the $\mathrm{Mg}^{2} \mathrm{p}$ - containing $\mathrm{Lu}_{3} \mathrm{Al}_{5} \mathrm{O}_{12}$ : Ce where they are stable up to $280 \mathrm{~K}$ [30]. The room temperature afterglow of GAGG:Ce,Mg arises from the recombination of the defects responsible for the $z 285 \mathrm{~K}$ peak. The peak at $380 \mathrm{~K}$ with $\mathrm{E}_{\mathrm{t}} \mathrm{z} 0.96 \mathrm{eV}$, characteristic only for the GAGG:Ce single crystal, is most probably connected with a single oxygen vacancy. Relatively small value of the trap depth ( $E_{t} \mathrm{z} 0.75 \mathrm{eV}$ ) and the corresponding frequency factor (fo $\sim 10^{6} \mathrm{~s}^{1}$ ) obtained for the TSL peak at $460 \mathrm{~K}$ indicate the hole origin of this peak. Indeed, in Ref. [36], the fo values for the hole trap related TSL glow curve peaks were found to be by $2 \mathrm{e} 3$ orders of magnitude smaller as compared to the close electron trap related TSL peaks. It is not excluded that the peak at about $440 \mathrm{~K}$ in GAGG:Ce,Mg is also of a hole origin.

From the dependence of the TSL peak intensity on the irradia-tion temperature $T_{i r r}$ (Fig. 12), the activation energy $E_{a}$ was deter-mined for the TSL peaks formation. Taking into account the data of [14], we expected to obtain the smaller $\mathrm{E}_{\mathrm{a}}$ value for GAGG:Ce, $\mathrm{Mg}$ as compared with GAGG:Ce. However, the $E_{a}$ values, indicating the position of the $5 \mathrm{~d}_{1}$ excited level of $\mathrm{Ce}^{3 \mathrm{p}}$ with respect to the bottom of the $\mathrm{CB}$, are very close in the GAGG:Ce and GAGG:Ce,Mg crystals $\left(E_{a} 1 / 40.21 \pm 0.01 \mathrm{eV}\right.$ and $E_{a} 1 / 40.22 \pm 0.01 \mathrm{eV}$, respectively). It should also be noted that at the temperature dependence of the $5 \mathrm{~d}_{1}$ e $4 \mathrm{f}$ luminescence intensity (Fig. 2), the stage with the activation energy $E_{q}$ z $0.21 \mathrm{e} 0.22 \mathrm{eV}$, caused by the thermally stimulated transitions of the electron from the $5 \mathrm{~d}_{1}$ excited level of $\mathrm{Ce}^{3 \mathrm{~b}}$ to the $\mathrm{CB}$, is also observed but only in the small temperature range between $360 \mathrm{~K}$ and $400 \mathrm{~K}$.

A small difference in the $\mathrm{E}_{\mathrm{a}}$ values observed for the investigated 
GAGG:Ce and GAGG:Ce, Mg crystals can be caused by slightly different Ga contents in these two crystals (x $1 / 42.831$ and x $1 / 42.694$, respectively) (for more details, see Ref. [23]). Therefore, strongly different activation energies of the luminescence thermal quenching reported for GAGG:Ce and GAGG:Ce,Ca in Ref. [14] are most probably caused by different Ga contents in these crystals.

\section{Conclusions}

Unlike the scintillation characteristics, where the substantial shortening of both the rise time and the decay time has been observed in Ref. [19], no noticeable influence of $\mathrm{Mg}^{2} \mathrm{p}$ on the photo-and X-ray excited luminescence characteristics of GAGG:Ce single crystals is found in this work. Under photoexcitation in the $\mathrm{Ce}^{3 \mathrm{p}}$ - and $\mathrm{Gd}^{3 \mathrm{p}}$ - related absorption bands, no rise of the photo-luminescence intensity in time with the rise time value above 1 nanosecond is observed neither in GAGG:Ce,Mg nor in GAGG:Ce crystals. The position of the $5 \mathrm{~d}_{1}$ excited level of $\mathrm{Ce}^{3} \mathrm{p}$ with respect to the conduction band is not influenced by $\mathrm{Mg}^{2} \mathrm{p}$ as well. These data allow to conclude that $\mathrm{Mg}^{2} \mathrm{p}$ ions do not noticeably perturb the energy levels of neither $\mathrm{Ce}^{3 \mathrm{p}}$ nor $\mathrm{Ce}^{4 \mathrm{p}}$ ions.

At the same time, the co-doping with $\mathrm{Mg}^{2} \mathrm{p}$ results not only in the strong reduction of afterglow but also in a drastic decrease of the thermally stimulated luminescence intensity in the whole investigated temperature range $(\mathrm{T}<500 \mathrm{~K})$, which indicates a strong decrease of the concentration of intrinsic crystal lattice de-fects. A positive influence of $\mathrm{Mg}^{2} \mathrm{p}$ on the TSL characteristics of GAGG:Ce is mainly caused by the formation of $\mathrm{Ce}^{4 \mathrm{p}}$ ions as effective electron traps which successfully compete with the intrinsic electron traps in the crystal lattice of GAGG [19]. Additionally, the co-doping with $\mathrm{Mg}^{2 \mathrm{p}}$ can result in the suppression of the number of single (noncompensated) cation and oxygen vacancies due to the formation of their associates with $\mathrm{Ce}^{4 \mathrm{p}}$ and $\mathrm{Mg}^{2} \mathrm{p}$ ions, respectively. Indeed, the compensation of the excess charge of the single va-cancies can considerably reduce the efficiency of trapping of charge carriers. The formation of the antisite defects of the type of $\mathrm{Gd}^{3} \mathrm{p}_{\mathrm{Ga}}$ or $\mathrm{Gd}^{3} \mathrm{p}_{\mathrm{Al}}$ needs the presence of volumecompensating vacancies due to a strong difference in ionic radii between the $\mathrm{Gd}^{3 \mathrm{~b}}$ ion and the $\mathrm{Ga}^{3 \mathrm{~b}}$ or $\mathrm{Al}^{3 \mathrm{~b}}$ ions. Therefore, the $\mathrm{Mg}^{2} \mathrm{p}$ - induced suppression of the number of single vacancies might result in the decreasing concentration of the antisite defects as well.

Besides, the $\mathrm{Mg}^{2 p}$ - induced changes in the defects structure appear also in much faster decay of the afterglow and in the change of the shape of the TSL glow curve. The decrease of the scintillation light yield in GAGG:Ce, $\mathrm{Mg}$ as compared to GAGG:Ce can be due to nonradiative recombination of electrons and holes around the $\mathrm{O}$ - based complex defects.

Thus, the $\mathrm{Mg}^{2} \mathrm{p}$ - induced changes in the concentration, origin and structure of the impurity and intrinsic defects in the GAGG:Ce crystal lattice lead to both the considerable improvement of the timing performance of GAGG:Ce (due to the formation of $\mathrm{Ce}^{4 \mathrm{p}}$ centers) and decrease of the scintillation light yield (about 1.3 times) reported in Ref. [19]. However, taking into account an extremely high light yield of 58000 photon/MeV and the energy resolution of 4.2\%@662 keV obtained for GAGG:Ce single crystals in Ref. [11], high density of this material $\left(6.63 \mathrm{~g} / \mathrm{cm}^{3}\right)$, excellent timing characteristics, low afterglow, and very good radiation hardness [19], GAGG:Ce,Mg can be considered as a very promising scintil-lating material for application in medical imaging and high energy physics detectors.

\section{Acknowledgments}

The work was supported by the Institutional Research Funding IUT02-26 of the Estonian Ministry of Education and Research and the project 16-15569S of the Czech Science Foundation.

\section{References}

[1] K. Kamada, T. Endo, K. Tsutumi, T. Yanagida, Y. Fujimoto, A. Fukabori, A. Yoshikawa, J. Pejchal, M. Nikl, Cryst. Growth Des. 11 (2011) 4484e4490.

[2] K. Kamada, T. Yanagida, T. Endo, K. Tsutumi, Y. Usuki, M. Nikl, Y. Fujimoto, A. Fukabori, A. Yoshikawa, J. Cryst. Growth 352 (2012) 88e90.

[3] K. Kamada, T. Yanagida, J. Pejchal, M. Nikl, T. Endo, K. Tsutsumi, Y. Fujimoto, A. Fukabori, A. Yoshikawa, IEEE Trans. Nucl. Sci. 59 (2012) $2112 \mathrm{e} 2115$.

[4] M. Nikl, A. Yoshikawa, K. Kamada, K. Nejezchleb, C.R. Stanek, J.A. Mares, K. Blazek, Prog. Cryst. Growth Charact. Mater. 59 (2013) 47 e72.

[5] M. Tyagi, F. Meng, M. Koschan, S.B. Donnald, H. Rothfuss, C.L. Melcher, J. Phys. D. Appl. Phys. 46 (2013) 475302.

[6] J.M. Ogieglo, A. Katelnikovas, A. Zych, T. Justel, A. Meijerink, C.R. Ronda, J. Phys Chem. A 117 (2013) 2479e2484.

[7] O. Sakthong, W. Chewpraditkul, Ch. Wanarak, J. Pejchal, K. Kamada, A. Yoshikawa, G.P. Pazzi, M. Nikl, Opt. Mater. 36 (2013) 568e571.

[8] T. Yanagida, K. Kamada, Y. Fujimoto, H. Yagi, T. Yanagitani, Opt. Mater. 35 (2013) $2480 \mathrm{e} 2485$.

[9] W. Drozdowski, K. Brylev, M.E. Witkowski, A.J. Wojtowicz, P. Solarz, K. Kamada, A. Yoshikawa, Opt. Mater. 36 (2014) 1665e1669.

[10] K. Brylew, W. Drozdowski, A.J. Wojtowicz, K. Kamada, A. Yoshikawa, J. Lumin. 154 (2014) 452 e457.

[11] K. Kamada, S. Kurosawa, P. Prusa, M. Nikl, V.V. Kochurikhin, T. Endo, K. Tsutumi, H. Sato, Y. Yokota, K. Sugiyama, A. Yoshikawa, Opt. Mater. 36 (2014) 1942 e1945.

[12] O. Sakthong, W. Chewpraditkul, Ch. Wanarak, K. Kamada, A. Yoshikawa, P. Prusa, M. Nikl, Nucl. Instr. Meth. Phys. Res. A 751 (2014) 1 e5.

[13] M. Kitaura, A. Sato, K. Kamada, A. Ohnishi, M. Sasaki, J. Appl. Phys. 115 (2014) 083517.

[14] Y. Wu, F. Meng, Q. Li, M. Koschan, C.L. Melcher, Phys. Rev. Appl. 2 (2014) 044009

[15] K. Kamada, M. Nikl, S. Kurosawa, A. Beitlerova, A. Nagura, Y. Shoji, J. Pejchal, Y. Ohashi, Y. Yokota, A. Yoshikawa, Opt. Mater. 41 (2015) 63 e66.

[16] M. Kitaura, A. Sato, K. Kamada, S. Kurosawa, A. Ohnishi, M. Sasaki, K. Hara, Opt. Mater. 41 (2015) 45e48.

[17] P. Sibczynski, J. Iwanowska-Hanke, M. Moszynski, L. Swiderski, M. Szawlowski, M. Grodzicka, T. Szczesniak, K. Kamada, A. Yoshikawa, Nucl. Instr. Meth. Phys. Res. A 772 (2015) $112 \mathrm{e} 117$

[18] P. Prusa, M. Kucera, J.A. Mares, Z. Onderisinova, M. Hanus, V. Babin, A. Beitlerova, M. Nikl, Cryst. Growth Des. 15 (2015) 3715 e3723.

[19] M.T. Lucchini, V. Babin, P. Bohacek, S. Gundacker, K. Kamada, M. Nikl, A. Petrosyan, A. Yoshikawa, E. Auffray, Nucl. Instr. Meth. Phys. Res. A 816 (2016) $176 \mathrm{e} 183$.

[20] A. Yoshikawa, K. Kamada, S. Kurosawa, Y. Shoji, Y. Yokota, V.I. Chani, J. Lumin. 169 (2016) $387 \mathrm{e} 393$

[21] M. Kitaura, K. Kamada, S. Kurosawa, J. Azuma, A. Ohnishi, A. Yamaji, K. Hara, Appl. Phys. Express 9 (2016) 072602.

[22] K. Kamada, Y. Shoji, V.V. Kochurikhin, A. Nagura, S. Okumura, S. Yamamoto, J.Y Yeom, S. Kurosawa, J. Pejchal, Y. Yokota, Y. Ohashi, M. Nikl, M. Yoshino, A. Yoshikawa, IEEE Trans. Nucl. Sci. 63 (2016) 443 e447.

[23] V. Babin, A. Krasnikov, M. Kucera, M. Nikl, S. Zazubovich, Opt. Mater. 62 (2016) $465 \mathrm{e} 474$.

[24] V. Babin, K. Chernenko, M. Kucera, M. Nikl, S. Zazubovich, J. Lumin. 179 (2016) $487 \mathrm{e} 495$.

[25] M. Nikl, E. Mihokova, J. Pejchal, A. Vedda, Yu. Zorenko, K. Nejezchleb, Phys. Status Solidi B 242 (2005) R119eR121.

[26] Yu. Zorenko, V. Gorbenko, I. Konstankevych, A. Voloshinovskii, G. Stryganyuk, V. Mikhailin, V. Kolobanov, D. Spassky, J. Lumin. 114 (2005) 85e94.

[27] H. Przybylinska, A. Wittlin, Chong-Geng Ma, M.G. Brik, A. Kaminska, P. Sybilski, Yu. Zorenko, M. Nikl, V. Gorbenko, A. Fedorov, M. Kucera, A. Suchocki, Opt. Mater. 36 (2014) 1515e1519.

[28] T. K€arner, V.V. Laguta, M. Nikl, T. Shalapska, S. Zazubovich, J. Phys. D. Appl. Phys 47 (2014) 065303

[29] S. Liu, X. Feng, Z. Zhou, M. Nikl, Y. Shi, Y. Pan, Phys. Status Solidi RRL 8 (2014) $105 e 109$.

[30] C. Hu, S. Liu, M. Fasoli, A. Vedda, M. Nikl, X. Feng, Y. Pan, Phys. Status Solidi RRL 9 (2015) 245e249. Opt. Mater. 45(2015) 252e257.

[31] A. Vedda, M. Nikl, M. Fasoli, E. Mihokova, J. Pechal, M. Dusek, G. Ren, C.R. Stanek, K.J. McClellan, D.D. Byler, Phys. Rev. B 78 (2008) 195123.

[32] R. Chen, S.W.S. McKeever, Theory of Thermoluminescence and Related Phe-nomena, World Scientific Pub. Co., 1997.

[33] P. Dorenbos, J. Lumin. 134 (2013) $310 \mathrm{e} 318$.

[34] V. Babin, M. Nikl, K. Kamada, A. Beitlerova, A. Yoshikawa, J. Phys. D. Appl. Phys. 46 (2013) 365303

[35] K. Bartosiewicz, V. Babin, K. Kamada, A. Yoshikawa, M. Nikl, J. Lumin. 166 (2015) $117 \mathrm{e} 122$.

[36] T. K€arner, V. Laguta, M. Nikl, S. Zazubovich, Phys. Status. Solidi B 251 (2014) $741 \mathrm{e} 747$.

[37] V. Jary, A. Krasnikov, M. Nikl, S. Zazubovich, Phys. Status Solidi B 252 (2015), $274 \mathrm{e} 271$. 